\title{
Central amygdala CRF pathways in alcohol dependence
}

\section{Giordano de Guglielmo, ${ }^{1}$ Marsida Kallupi, ${ }^{1}$ Matthew B. Pomrenze, ${ }^{2}$ Elena Crawford, ${ }^{1}$}

Sierra Simpson, ${ }^{1}$ Paul Schweitzer, ${ }^{1}$ George F. Koob, ${ }^{3}$ Robert O. Messing, ${ }^{2}$ Olivier George ${ }^{1, *}$

${ }^{1}$ Department of Neuroscience, The Scripps Research Institute, La Jolla, CA 92037 USA

${ }^{2}$ Division of Pharmacology and Toxicology, College of Pharmacy, The University of Texas at Austin, Austin, TX, USA

${ }^{3}$ National Institute on Drug Abuse, National Institutes of Health, Baltimore, MD 21224, USA

*Corresponding author:

Dr. Olivier George, Department of Neuroscience, The Scripps Research Institute, 10550 North Torrey Pines Road, SP30-2400, La Jolla, CA 92037, USA. Tel: +1 858784 7102. Fax: +1 858

784 7405. E-mail: ogeorge@scripps.edu 


\begin{abstract}
Alcohol withdrawal activates a neuronal ensemble in the central nucleus of the amygdala (CeA) that is responsible for high levels of uncontrolled alcohol drinking. However, the neuronal phenotypes and circuits controlled by these neurons are unknown. We investigated the cellular identity of this CeA neuronal ensemble and found that most neurons expressed corticotropinreleasing factor (CRF). Using Crh-Cre transgenic rats combined with in vivo optogenetics, we tested the role of CeA CRF neurons and their projections in excessive alcohol self-administration during withdrawal. Rats were injected with AAV-DIO-NpHR-eYFP or AAV-DIO-eYFP and implanted with optical fibers over the CeA. Animals were then exposed to chronic intermittent ethanol vapor to induce alcohol dependence. Inactivation of CeA CRF neurons decreased alcohol drinking in dependent rats to non-dependent levels and completely suppressed activation of the CeA neuronal ensemble ( $\mathrm{Fos}^{+}$neurons) during withdrawal. No effects were observed on water or saccharin self-administration. In a second experiment, CeA CRF neurons were infected with AAV-DIO-NpHR-eYFP and optical fibers were implanted into downstream projection regions, including the bed nucleus of the stria terminalis (BNST), lateral hypothalamus (LH), parasubthalamic nucleus (pSTN), substantia innominata (SI), and parabrachial nuclei (PBN). Optogenetic inactivation of CRF terminals in the BNST reduced alcohol drinking and withdrawal signs, whereas inactivation of all other projections had no effect. These results demonstrate that CeA CRF neurons and their projections to the BNST drive excessive alcohol drinking and withdrawal in dependent rats.
\end{abstract}




\section{Introduction}

Alcoholism is a chronic relapsing disorder associated with compulsive drinking, loss of control over intake, and emergence of a negative emotional state during abstinence from the drug (Koob et al, 2004). Animal and human studies implicated the central nucleus of the amygdala (CeA) in alcohol use disorders (Janak and Tye, 2015). In fact, it has been shown that chronic alcohol use alters neuronal transmission in the CeA (Roberto et al, 2012) and that the CeA stores memory traces related to the smell and taste of alcohol that drives relapse (Barak et al, 2013). Importantly, activation of a specific neuronal ensemble in the CeA during alcohol withdrawal is causally related to the excessive alcohol drinking that is observed in alcohol-dependent rats (de Guglielmo et al, 2016). However, the cellular phenotypes of these neurons and brain regions that are controlled by this neuronal ensemble are unknown. Moreover, activation of corticotropinreleasing factor $1\left(\mathrm{CRF}_{1}\right)$ receptors in the $\mathrm{CeA}$ is required for excessive alcohol drinking in dependent rats, but no direct evidence has been provided to date that activation of CeA CRF neurons is required for alcohol drinking. Indeed, extracellular levels of CRF in the CeA increase during withdrawal from chronic alcohol exposure (Koob, 2008; Koob et al, 2004; Merlo Pich et al, 1995; Olive et al, 2002), and systemic and intra-CeA administration of specific $\mathrm{CRF}_{1}$ antagonists reduce both the negative emotional states of alcohol withdrawal and alcohol drinking in dependent rats (Funk et al, 2006; Funk et al, 2007; Gehlert et al, 2007; Koob, 2008). Despite this substantial pharmacology evidence, no study has shown that the inactivation of CeA CRF neurons per se (not $\mathrm{CRF}_{1}$ receptors) is responsible for excessive alcohol drinking during acute withdrawal. This is critical because activation of $\mathrm{CeA} \mathrm{CRF}_{1}$ receptors could result from the activation of CRF neurons that are located in other brain regions (bed nucleus of the stria 
terminalis [BNST], lateral hypothalamus [LH], parasubthalamic nucleus [pSTN]) that project to the $\mathrm{CeA}$.

We first hypothesized that CRF neurons are critical for recruitment of the CeA neuronal ensemble during alcohol withdrawal. To test this hypothesis, we used Crh-Cre transgenic rats combined with in vivo optogenetics and immediate early gene brain mapping. We then dissected the role of the different downstream CeA CRF pathways in alcohol dependence using optogenetic inactivation of CeA CRF terminals that target the BNST ( $\mathrm{CRF}^{\mathrm{CeA}-\mathrm{BNST}}$ ), LH and

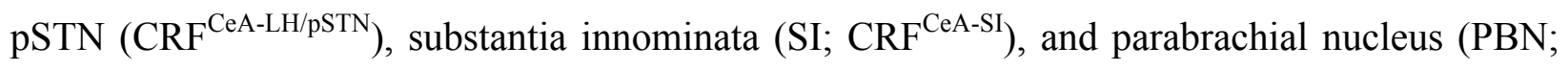
$\mathrm{CRF}^{\mathrm{CeA}-\mathrm{PBN}}$; Pomrenze et al, 2015).

\section{Materials and Methods}

\section{Subjects}

Adult male Crh-Cre rats, weighing 200-225 g at the beginning of the experiments, were housed in groups of two per cage (self-administration groups) in a temperature-controlled $\left(22^{\circ} \mathrm{C}\right)$ vivarium on a $12 \mathrm{~h} / 12 \mathrm{~h}$ light/dark cycle (lights on at 10:00 PM) with ad libitum access to food and water. All of the behavioral tests were conducted during the dark phase of the light/dark cycle. All of the procedures adhered to the National Institutes of Health Guide for the Care and Use of Laboratory Animals and were approved by the Institutional Animal Care and Use Committee of The Scripps Research Institute.

\section{Operant self-administration}

Self-administration sessions were conducted in standard operant conditioning chambers (Med Associates, St. Albans, VT, USA). For alcohol self-administration studies, animals were first 
trained to self-administer $10 \%(\mathrm{w} / \mathrm{v})$ alcohol and water solutions until a stable response pattern (20 \pm 5 rewards) was maintained. Rats were then subjected to an overnight session in the operant chambers with access to one lever (right lever) that delivered water (fixed-ratio 1 [FR1]). Food was available ad libitum during this training. After 1 day off, rats were subjected to a $2 \mathrm{~h}$ session (FR1) for 1 day and a $1 \mathrm{~h}$ session (FR1) the next day, with one lever delivering alcohol (right lever). All of the subsequent alcohol self-administration sessions lasted $30 \mathrm{~min}$. Rats were allowed to self-administer a 10\% (w/v) alcohol solution (right lever) and water (left lever) on an FR1 schedule of reinforcement (i.e., each operant response was reinforced with $0.1 \mathrm{ml}$ of the solution). For saccharin self-administration, rats underwent daily 30 min FR1 sessions. Responses on the right lever resulted in the delivery of $0.1 \mathrm{ml}$ of saccharin $(0.04 \%, \mathrm{w} / \mathrm{v})$. Lever presses on the left lever delivered $0.1 \mathrm{ml}$ of water. This procedure lasted 13 days until a stable baseline of intake was achieved.

\section{Alcohol vapor chambers}

Rats were trained to self-administer alcohol in the operant chambers. Once a stable baseline of alcohol intake was reached, the rats were made dependent by chronic intermittent exposure to alcohol vapors. They underwent cycles of $14 \mathrm{~h}$ on (blood alcohol levels during vapor exposure ranged between 150 and $250 \mathrm{mg} \%$ ) and $10 \mathrm{~h} \mathrm{off,} \mathrm{during} \mathrm{which} \mathrm{behavioral} \mathrm{testing} \mathrm{for} \mathrm{acute}$ withdrawal occurred (i.e., 6-8 h after vapor was turned off, when brain and blood alcohol levels are negligible). In this model, rats exhibit somatic and motivational signs of withdrawal (Vendruscolo and Roberts, 2014). 
Behavioral testing occurred three times per week. Rats were tested for alcohol or saccharin (and water) self-administration on an FR1 schedule of reinforcement in 30-min sessions. Behavioral signs of withdrawal were measured using a rating scale that was adapted from a previous study (Macey et al, 1996) and included ventromedial limb retraction (VLR), irritability to touch (vocalization), tail rigidity, abnormal gait, and body tremors. Each sign was given a score of 0-2, based on the following severity scale: $0=$ no sign, $1=$ moderate, $2=$ severe. The sum of the four observation scores (0-8) was used as an operational measure of withdrawal severity.

\section{Intracranial surgery}

Rats were anesthetized with isoflurane $(5 \% \mathrm{v} / \mathrm{v})$ and secured in a stereotaxic frame. Credependent adeno-associated viruses AAV-DIO-eNpHR3.0-eYFP or AAV-DIO-eYFP (UNC Vector Core, University of North Carolina, Chapel Hill) were injected bilaterally or unilaterally in the CeA (coordinates from Bregma: - $2.6 \mathrm{~mm} \mathrm{AP}, \pm 4.2 \mathrm{~mm} \mathrm{ML},-6.1 \mathrm{~mm} \mathrm{DV}$ from skull surface) through a stainless-steel injector that was $2 \mathrm{~mm}$ longer than the guide cannula (so that the tip protruded into the area) and connected to a $10 \mu \mathrm{l}$ Hamilton syringe, which was controlled by an UltraMicroPump (WPI, Sarasota, FL, USA). Virus was injected (1.0 $\mu 1,100 \mathrm{nl} / \mathrm{min})$ over $10 \mathrm{~min}$ followed by an additional $10 \mathrm{~min}$ to allow the diffusion of viral particles. Rats used for behavioral experiments were then implanted bilaterally or unilaterally with chronic fiber optics above the CeA (coordinates from Bregma: AP $-2.6 \mathrm{~mm}, \mathrm{ML} \pm 4.2 \mathrm{~mm}, \mathrm{DV}-8.1 \mathrm{~mm}$ from skull surface), or unilaterally above the BNST (AP $-0.1, \mathrm{ML} \pm 1.4$, DV -6.7 from skull surface), the $\mathrm{LH} / \mathrm{pSTN}$ (AP -4.2, ML $\pm 1.2, \mathrm{DV}-8.7$ from skull surface), the SI (AP - 0.1, ML $\pm 1.8, \mathrm{DV}-8.5$ from skull surface) or the PBN (AP $-9.2, \mathrm{ML} \pm 1.8, \mathrm{DV}-6.5$ from skull surface). Following surgery, rats were allowed to recover for 1 week. 


\section{Locomotor activity}

Locomotor activity and anxiety-like behavior were evaluated in an opaque open field apparatus $(100 \mathrm{~cm} \times 100 \mathrm{~cm} \times 40 \mathrm{~cm})$ that was divided into $20 \mathrm{~cm} \times 20 \mathrm{~cm}$ squares. On the experimental day, the animals were placed in the center of the open field, and locomotor activity (number of lines crossed), the time in the center, total distance traveled, and entries into the center were scored for 10 min. Behavior was videotaped and analyzed with Any Maze software.

\section{Optical inhibition}

Optical probes were constructed, in which the fiber optic $(200 \mu \mathrm{m}$ core, multimode, 0.37 NA) was inserted and glued into a ceramic ferrule. The fiber optic and ferrule were then glued to a metallic cannula and closed with a dust cap. The fiber optic length was then adjusted based on the brain area of interest to not leave a gap between the skull and cannula during surgery. The other end of the fiber optic (FC/PC connection) was attached to a fiber splitter $(2 \mathrm{x} 1)$ that permitted simultaneous, bilateral illumination. The single end of the splitter was attached to a rotating optical commutator (Doric Lenses) to permit free movement of the rat. The commutator was connected to a fiber that was connected to a laser (DPSS, 200 or $300 \mathrm{~mW}, 532 \mathrm{~nm}$, with a multimode fiber coupler for an FC/PC connection; OEM Laser Systems). Prior to the experiments, the light output of the fiber optic was adjusted to approximately $10 \mathrm{~mW}$, as measured by an optical power meter. Based on measurements in the mammalian brain (Deisseroth, 2012), assuming a geometric loss of light, a light output of $10 \mathrm{~mW}$ that is measured by a standard optical power at the tip of a fiber with an NA of 0.37 and fiber core radius of 200 $\mu \mathrm{m}$ will produce $\sim 1 \mathrm{~mW} / \mathrm{mm}^{2}$ of light up to $1 \mathrm{~mm}$ directly away from the fiber tip, which is the 
minimum amount necessary to produce opsin activation (Gradinaru et al, 2009; Tye et al, 2011). Based on in vivo measurements of the shape of the light output in mammalian brain tissue, these parameters would be expected to provide sufficient light for opsin activation in at least $0.4 \mathrm{~mm}^{3}$ of tissue (Yizhar et al, 2011). Fiber optics were implanted at the same time as the virus injections, and the animals were habituated to tethering to the commutator for several selfadministration sessions before beginning the experiments. On the test days, the rats received optical inhibition paired with alcohol self-administration sessions, locomotor activity assessments, or withdrawal score assessments.

\section{Recruitment of CeA CRF neurons during alcohol withdrawal}

Rats were trained to self-administer $10 \%$ alcohol and made dependent on alcohol using the chronic intermittent exposure model. After the stabilization of excessive drinking, the animals were transcardially perfused. The brains were then harvested, postfixed, and sectioned at $40 \mu \mathrm{m}$.

Effect of optogenetic inhibition of CeA CRF neurons on alcohol and saccharin selfadministration in nondependent and alcohol-dependent rats

Animals were injected with AAV-DIO-eNpHR3.0-eYFP or AAV-DIO-eYFP and implanted with bilateral fiber optics over the CeA. One week after surgery, the rats were trained to selfadminister $10 \%$ alcohol until they reached a stable baseline of intake. At this point, rats were tested for alcohol self-administration during optical inhibition of CeA CRF neurons. Sham optical inhibition sessions were performed before and after the test session. The animals were then placed in the alcohol vapor chambers and 3 weeks later underwent the alcohol selfadministration escalation phase. When the escalation of alcohol intake was achieved, animals 
were tested for the effects of the optical inhibition of CeA CRF neurons as described above. The effect of optical inhibition on somatic withdrawal signs was also assessed.

At the end of this phase, rats were trained to self-administer saccharin for several sessions until a stable baseline of responses was reached. They were then tested for the effects of the optical inhibition of CeA CRF neurons on saccharin self-administration. The effects of optical inhibition on locomotor activity were also assessed.

Dissection of the role of different CeA CRF pathways on alcohol and saccharin selfadministration in alcohol-dependent rats

Crh-Cre rats were bilaterally infused with AAV-DIO-NpHR-eYFP in the CeA, unilaterally implanted with fiber optics over the CeA, BNST, PBN, SI, or LH, and made dependent on alcohol using the chronic intermittent exposure model. After escalation of drinking, the animals were tested for the effect of the optogenetic inhibition of CeA CRF projections on alcohol drinking, alcohol withdrawal signs, and saccharin self-administration.

\section{Immunohistochemistry}

Crh-Cre rats were unilaterally prepared with AAV-DIO-NpHR-EYFP and an optic fiber in the $\mathrm{CeA}$ and tested for the effect of inhibition of $\mathrm{CeA} C R F$ neurons for 30 min during withdrawal $(8 \mathrm{~h})$ from chronic intermittent alcohol. Ninety minutes later, the animals were deeply anesthetized and perfused with $100 \mathrm{~mL}$ of phosphate-buffered saline (PBS) followed by $400 \mathrm{~mL}$ of $4 \%$ paraformaldehyde. Brains were postfixed in $4 \%$ paraformaldehyde overnight and transferred to $30 \%$ sucrose in $\mathrm{PBS} / 0.1 \%$ azide solution at $4{ }^{\circ} \mathrm{C}$ for $2-3$ days. Brains were frozen in powdered dry ice and sectioned on a cryostat. Coronal sections were cut $40 \mu \mathrm{m}$ thick between 
bregma +4.2 and $-6.48 \mathrm{~mm}$ (Paxinos and Watson, 2005) and collected free-floating in PBS/0.1\% azide solution. Following three washes in PBS, the sections were incubated in $1 \%$ hydrogen peroxide/PBS to quench endogenous peroxidase activity, rinsed three times in PBS, and blocked for $60 \mathrm{~min}$ in PBS that contained $0.3 \%$ TritonX-100, $1 \mathrm{mg} / \mathrm{ml}$ bovine serum albumin, and 5\% normal donkey serum. Sections were incubated for $24 \mathrm{~h}$ at $4{ }^{\circ} \mathrm{C}$ with rabbit monoclonal anti-Fos antibody (Cell Signaling Technologies, catalog no. 2250) diluted 1:1000 in PBS/0.5\% Tween20 and 5\% normal donkey serum. The sections were washed again with PBS and incubated for $1 \mathrm{~h}$ in undiluted Rabbit ImmPress HRP reagent (Vector Laboratories). After washing in PBS, the sections were developed for 2-6 min in Vector peroxidase DAB substrate (Vector Labs) enhanced with nickel chloride. Following PBS rinses, the sections were mounted on coated slides (Fisher Super Frost Plus), air dried, dehydrated through a graded series of alcohol, cleared with Citrasolv (Fisher Scientific), and coverslipped with DPX (Sigma).

Quantitative analysis to obtain unbiased estimates of the total number of Fos + cell bodies was performed on a Zeiss Axiophot Microscope equipped with MicroBrightField Stereo Investigator software (Colchester, VT, USA), a three-axis Mac 5000 motorized stage (Ludl Electronics Products, Hawthorne, NY, USA), a Q Imaging Retiga 2000R color digital camera, and PCI color frame grabber.

Fluorescent immunohistochemistry was used to characterize the type (CRF) and number $(\mathrm{NeuN})$ of neurons that were activated $\left(\mathrm{Fos}^{+}\right)$during alcohol withdrawal. Coronal sections were cut $40 \mu \mathrm{m}$ thick between bregma -2.0 and $-5.0 \mathrm{~mm}$ (Paxinos et al, 2005). We determined the proportion of all neurons expressing Fos during alcohol withdrawal by double-labeling for Fos and the neuron-specific protein NeuN, as well as the population of activated CRF neurons in the CeA by double labeling for Fos and CRF. 
For Fos/NeuN and Fos/CRF double-labeling, $40 \mu \mathrm{m}$ sections were washed three times in PBS and permeabilized/blocked for $60 \mathrm{~min}$ in PBS with $0.2 \%$ Triton X-100, 5\% normal donkey serum, and 3\% bovine serum albumin (blocking solution). Sections were incubated in primary antibodies diluted in blocking solution for $24 \mathrm{~h}$ on a shaker at room temperature. Primary antibodies were used at the following concentrations: anti-Fos (Millipore, catalog no. AB4532, 1:500) and anti-NeuN (Millipore, catalog no. MAB377, 1:1000). Sections were washed three times for 10 min in PBS and incubated with fluorescently labeled secondary antibodies diluted in PBS for $2 \mathrm{~h}$ on a shaker at room temperature. Species-specific secondary antibodies used were Alexa Fluor 488 (1:500, Invitrogen, catalog no. A-10042), Alexa Fluor 568 (1:500, Invitrogen, catalog no. S-11249), and Alexa Fluor 647 (1:500, Invitrogen, catalog no. A-21447). After labeling, the sections were washed three times in PBS for 10 min, mounted on Fisher Superfrost Plus slides (catalog no. 12-550-15), and coverslipped with PVA-Dabco (Sigma).

Three sections were bilaterally analyzed for each rat. Cells were identified as neurons based on standard morphology, and only neurons with a focused nucleus within the boundary of the CeA were counted. Counts from all images for each rat were averaged so that each rat was an $n$ of 1.

\section{Confocal acquisition and three-dimensional analysis}

Three-dimensional stacks of images were acquired with a 780 Laser Scanning Confocal microscope (Zeiss) using a $20 \times(1 \mu \mathrm{m}$ image slice $), 40 \times(0.6 \mu \mathrm{m}$ image slice $)$, or $63 \times(0.2 \mu \mathrm{m}$ image slice) objective to observe the entirety of the CeA. The system is equipped with a stitching stage and Zen software to reintegrate the tiled image stacks. Stitched z-series images of the entire CeA were imported into Imaris software (Bitplane-Andor) and FIJI for quantification. 
Slice preparation for whole-cell recordings

Crh-Cre rats $(n=5)$ expressing AAV-DIO-eNpHR-EYFP in the CeA for 4-5 weeks were deeply anesthetized with $3 \%$ isoflurane and then transcardially perfused with ice-cold oxygenated sucrose solution. The rats were then decapitated, and the brains were rapidly removed and placed into oxygenated $\left(95 \% \mathrm{O}_{2}, 5 \% \mathrm{CO}_{2}\right)$ ice-cold cutting solution that contained $206 \mathrm{mM}$ sucrose, $2.5 \mathrm{mM} \mathrm{KCl}, 1.2 \mathrm{mM} \mathrm{NaH}_{2} \mathrm{PO}_{4}, 7 \mathrm{mM} \mathrm{MgCl}$, $0.5 \mathrm{mM} \mathrm{CaCl}, 26 \mathrm{mM}$ $\mathrm{NaHCO}_{3}, 5 \mathrm{mM}$ glucose, and $5 \mathrm{mM}$ HEPES. CeA slices (300 um) thick were cut on a Vibratome (Leica VT1000S, Leica Microsystems, Buffalo Grove, IL, USA) and transferred to oxygenated artificial cerebrospinal fluid (aCSF) that contained $130 \mathrm{mM} \mathrm{NaCl}, 2.5 \mathrm{mM} \mathrm{KCl}$, $1.25 \mathrm{mM} \mathrm{NaH} 2 \mathrm{PO}_{4}, 1.5 \mathrm{mM} \mathrm{MgSO} \cdot 7 \mathrm{H}_{2} \mathrm{O}, 2.0 \mathrm{mM} \mathrm{CaCl}_{2}, 24 \mathrm{mM} \mathrm{NaHCO}$, and $10 \mathrm{mM}$ glucose. Slices were first incubated for $30 \mathrm{~min}$ at $37^{\circ} \mathrm{C}$ and then kept at room temperature for the remainder of the experiment. Individual slices were transferred to a recording chamber that was mounted on the stage of an upright microscope (Olympus BX50WI, Waltham MA, USA). Recordings were performed in continuous oxygenated aCSF that was perfused at a rate of 2-3 $\mathrm{ml} / \mathrm{min}$. Neurons were visualized with a $60 \times$ water immersion objective (Olympus), infrared differential interference contrast optics, and a charge-couple device camera (EXi Blue, QImaging, Surrey, Canada). Whole-cell recordings were performed using current clamp mode with a Multiclamp 700B amplifier, Digidata 1440A, and pClamp 10 software (Molecular Devices, Sunnyvale, CA, USA). Patch pipettes (4-7 M $\Omega$ ) were pulled from borosilicate glass (Warner Instruments, Hamden, CT, USA) and filled with the following internal solution: 70 $\mathrm{mM} \mathrm{KMeSO}_{4}, 55 \mathrm{mM} \mathrm{KCl}, 10 \mathrm{mM} \mathrm{NaCl}, 2 \mathrm{mM} \mathrm{MgCl}_{2}, 10 \mathrm{mM}$ HEPES, $2 \mathrm{mM} \mathrm{Mg}$-ATP, and $0.2 \mathrm{mM}$ Na-GTP. 
To study light-induced neuronal inhibition, a green laser (532 nm) was switched on for $6.5 \mathrm{~s}$ by a Master- 8 stimulator (AMPI, Jerusalem, Israel) to generate trains at a frequency of 15 Hz. Neurons that expressed eNpHR within the CeA were visualized with differential interference contrast and widefield fluorescence imaging using an Olympus $60 \times$ immersion objective. To identify eNpHR-expressing neurons, a Lambda DG-4 light source was used with an in-line EX540/EM630 filter set. A Mosaic 3 pattern illuminator (Andor Instruments, Belfast, UK) coupled to a $532 \mathrm{~nm}$ light-emitting diode (CoolLED Limited, Andover, UK) was attached to the microscope and used for light delivery $\left(10 \mathrm{~mW} / \mathrm{mm}^{2}\right.$, to approximate output in the behavioral experiments) through the objective within the slice preparation.

\section{Histology}

Following completion of behavioral experiments, the rats were deeply anaesthetized and transcardially perfused. Brains were removed, postfixed, cryoprotexted in $30 \%$ sucrose, and sectioned at $40 \mu \mathrm{m}$ into coronal sections containing the CeA, BNST, and PBN. Brain slices were mounted on microscope slides and expression of viral vectors and/or optical fiber placements were examined for all of the rats using fluorescent microscopy. Rats that had no eYFP expression in the $\mathrm{CeA}$ or had fiber placements outside the target regions of interest were excluded from the behavioral analysis.

\section{Statistical analysis}

Data are expressed as mean $\pm \mathrm{SEM}$. For comparisons between only two groups, $p$ values were calculated using paired or unpaired $t$-tests as described in the figure legends. Comparisons across more than two groups were made using one-way analysis of variance (ANOVA), and two- 
way ANOVA was used when there was more than one independent variable. The Newman Keuls post hoc test was used following significance in the ANOVA. Withdrawal signs were analyzed by the nonparametric Mann-Whitney $U$ statistic, followed by Dunn's multiple-comparison test. The standard error of the mean is indicated by error bars for each group of data. Differences were considered significant at $p<0.05$. All of the data were analyzed using Statistica 7 software.

\section{Results}

\section{CeA CRF neurons are recruited during alcohol withdrawal}

At the end of the escalation phase and exposure to chronic intermittent ethanol vapor, rats averaged $45.1 \pm 7.2$ responses for alcohol compared with $17.5 \pm 3.4$ responses before exposure to chronic intermittent ethanol ( $p<0.01$; Fig 1.A). After the stabilization of excessive drinking, the animals were transcardially perfused. Withdrawal from alcohol vapor produced a significant increase in $\operatorname{Fos}^{+}$neurons in the $\mathrm{CeA}\left(t_{8}=6.16, p<0.001\right.$; Fig. 1B). This recruitment was limited to a small subpopulation of neurons in the CeA. Double-labeling with Fos/NeuN revealed that only $7-8 \%$ of all CeA neurons $(\mathrm{NeuN}+)$ were also Fos $^{+}\left(t_{8}=22.4, p<0.01\right.$; Supplementary Fig. S1). Double Fos-CRF immunohistochemistry showed that the total number of CRF neurons did not change between withdrawal rats and naive rats $\left(t_{8}=0.58, p=0.05\right.$; Fig. $\left.1 \mathrm{C}\right)$, but the number of $\mathrm{Fos}^{+} / \mathrm{CRF}^{+}$neurons in the CeA significantly increased during withdrawal $\left(t_{8}=6.24, p<0.001\right.$; Fig. 1D) and represented the majority of $\mathrm{Fos}^{+}$neurons $(80 \%)$.

\section{Validation of NpHR in CeA CRF neurons}

To confirm the functionality of $\mathrm{NpHR}$, electrophysiological recordings of neuronal activity from single neurons were performed in acute $\mathrm{CeA}$ slices from $\mathrm{Crh}$-Cre rats. CeA neurons were 
depolarized by current injection to evoke the sustained firing of action potentials, and $\mathrm{CRF}^{+}$ neurons were identified by visualization of eYFP fluorescence (Zhao et al, 2011). In six neurons that showed fluorescence that were held at $-52.9 \pm 0.4 \mathrm{mV}$, activation of a green laser (532 nm) using a $6.5 \mathrm{~s}$ train at $15 \mathrm{~Hz}$ (Haubensak et al, 2010) elicited hyperpolarization of $6.5 \pm 1.0 \mathrm{mV}$, concomitantly suppressing the firing of action potentials (Fig. 2C). In another six neurons that did not show fluorescence, similar exposure to the laser $(6.5 \mathrm{~s}$ at $15 \mathrm{~Hz})$ did not elicit any significant effect on resting potential $(-51.8 \pm 0.5 \mathrm{mV}$ hold, $0.5 \pm 0.3 \mathrm{mV}$ hyperpolarization; Fig. 2D).

Optogenetic inhibition of CeA CRF neurons reduces alcohol self-administration in alcoholdependent rats

In non-dependent animals, inhibition of CeA CRF neurons had no effect in both NpHR and control rats. The ANOVA did not reveal a main effect of group $\left(F_{1,14}=1.30, p>0.05\right)$ or treatment $\left(F_{1,28}=0.03, p>0.05\right)$ or a group $\times$ treatment interaction $\left(F_{1,28}=2.10, p>0.05\right)$. Water self-administration was unaffected by the green laser, with no effect of group $\left(F_{1,14}=0.17\right.$, $p>0.05)$ or treatment $\left(F_{1,28}=0.82, p>0.05\right)$ and no group $\times$ treatment interaction $\left(F_{1,28}=1.07\right.$, $p>0.05$; Fig. 3A).

After 6 weeks of chronic intermittent alcohol vapor exposure, the animals escalated their alcohol consumption $\left(F_{1,28}=0.82, p<0.001\right)$. The Newman Keuls post hoc test indicated a significant increase in alcohol self-administration starting from session 8 to session 12 compared with the first day of vapor exposure $(p<0.05$; Fig. 3B). Fig. 3C shows the effects of the optogenetic inhibition of CeA CRF neurons on alcohol (Fig. 3C.a) and water (Fig. 3C.b) selfadministration in alcohol-dependent rats. The mixed-factorial ANOVA indicated that both 
controls and NpHR rats escalated their alcohol intake after 5 weeks of vapor exposure $\left(F_{1,14}=\right.$ 14.9, $p<0.01 ; p<0.05, v s$. baseline pre-vapor, Newman Keuls post hoc test). Activation of the green laser selectively reduced alcohol self-administration in NpHR-injected rats. The ANOVA revealed a significant effect of treatment $\left(F_{2,28}=12.7, p<0.001\right)$ and a group $\times$ treatment interaction $\left(F_{2,28}=8.38, p<0.01\right)$ but no effect of group $\left(F_{1,14}=1.74, p>0.05\right)$. The Newman Keuls post hoc test indicated a selective reduction of alcohol intake in NpHR-injected rats. No effect of the inhibition of CeA CRF neurons was detected on water self-administration, with no effect of group $\left(F_{1,14}=0.7, p>0.05\right)$ or treatment $\left(F_{2,28}=0.22, p>0.05\right)$ and no group $\times$ treatment interaction $\left(F_{2,28}=2.44, p>0.05\right)$.

To verify that the effect of optical inhibition was not attributable to nonspecific effects of prolonged (30 $\mathrm{min}$ ) illumination of the $\mathrm{CeA}$ with the green laser, we measured alcohol drinking after only $5 \mathrm{~min}$ of illumination. No difference in the magnitude of the effects was observed between the first 5 min and entire 30 min session (Supplementary Fig. S2A).

To further test the behavioral specificity of optical inhibition of CeA CRF neurons on alcohol drinking, the animals were trained to self-administer saccharin and tested for the effects of the inhibition of CeA CRF neurons on saccharin intake. The mixed-factorial ANOVA did not reveal an effect of activation of the green laser in controls or NpHR rats on saccharin intake (group: $F_{1,14}=0.27, p>0.05$; treatment: $F_{2,28}=0.48, p>0.05$; group $\times$ treatment interaction: $F_{2,28}=0.06, p>0.05$ ) or water intake (group: $F_{1,14}=0.57, p>0.05$; treatment: $F_{2,28}=1.13, p>$ 0.05; group $\times$ treatment interaction: $\left.F_{2,28}=0.27, p>0.05\right)$.

The animals were finally tested in the open field for effects on locomotor activity and anxiety-like behavior. The $t$-tests did not reveal significant effects of exposure to the green laser between controls and NpHR-injected rats on the total distance traveled $\left(t_{8}=0.36, p>0.05\right)$ or 
time spent in the center $\left(t_{8}=0.36, p>0.05\right)$. Therefore optogenetic silencing of CeA CRF neurons selectively reduces alcohol self-administration in dependent rats without affecting locomotor activity or anxiety.

Unilateral inhibition of CeA CRF neurons reduces alcohol self-administration and Fos induction in the $C e A$

A separate group of Crh-Cre rats was bilaterally infused with AAV-DIO-NpHR-eYFP and implanted with unilateral fiber optics over the CeA (hemispheres with fiber optics were counterbalanced across al groups). The effect of the optogenetic inhibition of CeA CRF neurons on alcohol drinking, somatic signs of withdrawal, and saccharin self-administration were measured using the same chronic intermittent alcohol exposure protocol as in the previous experiments.

For alcohol drinking, the two-way repeated-measures ANOVA, with time and laser illumination as within-subjects factors, revealed significant effects of time $\left(F_{2,22}=16.36, p<\right.$ $0.001)$ and laser illumination $\left(F_{1,11}=6.62, p<0.05\right)$ and a time $\times$ laser illumination interaction $\left(F_{2,22}=13.15 ; p<0.001\right)$. The Newman Keuls post hoc test showed a significant reduction of alcohol self-administration when the green laser was turned on $(p<0.01, v s$. laser OFF; Fig. 4A).

A separate one-way ANOVA indicated that the animals presented escalation of alcohol intake compared with baseline pre-vapor exposure $\left(F_{6,66}=9.23, p<0.001\right)$. The escalation of alcohol drinking was observed only on days when the laser was off $(p<0.001)$ and was completely blocked by the optogenetic inhibition of CeA-CRF neurons, indicated by the Newman Keuls post hoc analysis. 
Immediately before the last two alcohol self-administration sessions, rats were observed for somatic signs of withdrawal. As shown in Fig. 4B, the laser ON group exhibited significant decreases in ventromedial limb retraction (Mann-Whitney $U=9.00, p<0.05$ ) and abnormal gait $(U=3.000, p<0.01)$. The sum of the five rating scores revealed a significant decrease in overall withdrawal severity $(U=4.5, p<0.05$; Fig. 4B, inset) during inhibition of CeA CRF neurons. The $t$-test did not indicate an effect of the inhibition of CeA CRF neurons on saccharin selfadministration $\left(t_{11}=0.321, p>0.05\right.$; Fig. $\left.4 \mathrm{C}\right)$.

A separate group of rats was tested for the effect of inhibition of CeA CRF neurons for 30 min during withdrawal $(8 \mathrm{~h})$ from chronic intermittent alcohol exposure on CeA Fos induction. The ANOVA revealed a significant effect of the optogenetic inhibition of CeA CRF neurons $\left(F_{3,2}=13.61, p<0.01\right)$. The Newman Keuls post hoc test indicated that after inhibition (laser $\mathrm{ON}$ ), the increase in $\mathrm{Fos}^{+}$neurons that was normally observed during withdrawal (laser OFF; $p<0.01$, laser OFF vs. naive) was completely prevented ( $p<0.01$, ON $v s$. OFF). Unilateral inhibition also partially affected the contralateral CeA, in which a significant decrease in $\mathrm{Fos}^{+}$neurons was observed on the contralateral side $(p<0.01, \mathrm{ON} /$ contralateral vs. OFF; Fig. 4D).

\section{Dissection of CeA CRF pathways in alcohol drinking in dependent rats}

Ventral bed nucleus of the stria terminalis. The two-way repeated-measures ANOVA, with time and laser as within-subjects factors, revealed significant effects of time $\left(F_{2,22}=9.18, p<0.01\right)$ and laser $\left(F_{1,11}=29.72, p<0.001\right)$ on alcohol drinking and a time $\times$ laser interaction $\left(F_{2,22}=\right.$ 5.31, $p<0.05)$. The Newman Keuls post hoc test showed a significant reduction of alcohol selfadministration when the green laser was turned $\mathrm{ON}(p<0.01, v s$. laser OFF; Fig. 5A.a). A 
separate one-way ANOVA indicated that the animals exhibited escalation of alcohol intake compared with baseline pre-vapor exposure $\left(F_{6,66}=11.43, p<0.0001\right)$. The Newman Keuls post hoc test indicated that rats showed escalation of alcohol drinking only on laser OFF days $(p<$ 0.001), whereas the animals exhibited a level of responding that was similar to baseline prevapor exposure during optogenetic inhibition of $\mathrm{CRF}^{\mathrm{CeA}-\mathrm{BNST}}$ terminals (Fig. 5A.a). Immediately before the last two alcohol self-administration sessions, the rats were observed for withdrawal signs $8 \mathrm{~h}$ into withdrawal. As shown in Fig. 5A.b, the laser ON group exhibited significant decreases in abnormal gait (Mann-Whitney $U=6.00, p<0.05)$ and body tremors $(U=10.50, p<$ 0.05). The sum of the five rating scores revealed a significant decrease in overall withdrawal severity $\left(U=1.5, p<0.01\right.$; Fig. 5A.b, inset) after inhibition of $\mathrm{CRF}^{\text {CeA-BNST }}$ terminals. The $t$-test did not reveal an effect of the inhibition of $\mathrm{CRF}^{\mathrm{CeA}-\mathrm{BNST}}$ terminals on saccharin selfadministration $\left(t_{11}=0.12, p>0.05\right.$; Fig. 5A.c $)$.

Substantia innominata. The two-way repeated-measures ANOVA, with time and laser as withinsubjects factors, revealed a significant effect of time $\left(F_{2,10}=15.10 ; p<0.001\right)$ but no effect of laser $\left(F_{1,5}=4.39, p>0.05\right)$ and no time $\times$ laser interaction $\left(F_{2,10}=3.66, p>0.05\right)$. A separate one-way ANOVA indicated that the animals exhibited escalation of alcohol intake compared with baseline pre-vapor exposure $\left(F_{6,30}=4.28, p<0.01\right)$. The escalation of alcohol intake was unaffected by optogenetic inhibition of $\mathrm{CRF}^{\mathrm{CeA}-\mathrm{SI}}$ terminals, indicated by the Newman Keuls post hoc test. Operant responding for alcohol remained high on both the laser ON and OFF days ( $p<0.05$ and $p<0.01$, respectively, vs. baseline; Fig. 5B.a). The optogenetic inhibition of $\mathrm{CRF}^{\mathrm{CeA}-\mathrm{SI}}$ terminals did not affect alcohol drinking $\left(t_{11}=0.49, p>0.05\right)$. Immediately before the last two alcohol self-administration sessions, the rats were observed for withdrawal signs. As 
shown in Fig. 5B.b, inhibition of $\mathrm{CRF}^{\mathrm{CeA}-\mathrm{SI}}$ terminals did not affect overall withdrawal severity ( $U=15.50, p>0.05$; Fig. 5B.b, inset). The $t$-test did not indicate an effect of inhibition of $\mathrm{CRF}^{\mathrm{CeA}-\mathrm{SI}}$ terminals on saccharin self-administration $\left(t_{5}=0.22, p>0.05\right.$; Fig. 5B.c).

Lateral hypothalamus/parasubthalamic nucleus. The two-way repeated-measures ANOVA, with time and laser as within-subjects factors, revealed a significant effect of time $\left(F_{2,10}=8.87, p<\right.$ $0.01)$ but no effect of laser $\left(F_{1,5}=0.78, p>0.05\right)$ and not time $\times$ laser interaction $\left(F_{2,10}=0.16, p\right.$ $>0.05$; Fig. 5C.a). A separate one-way ANOVA indicated that the animals exhibited escalation of alcohol intake compared with baseline pre-vapor exposure $\left(F_{6,30}=4.28, p<0.01\right)$. The escalation of alcohol intake was unaffected by optogenetic inhibition of $\mathrm{CRF}^{\mathrm{CeA}-\mathrm{LH} / \mathrm{pSTN}}$ terminals, indicated by the Newman Keuls post hoc test. Operant responding for alcohol remained high on both the laser $\mathrm{ON}$ and OFF days (both $p<0.05$, vs. baseline; Fig. 5C.a). Immediately before the last two alcohol self-administration sessions, rats were observed for withdrawal signs. As shown in Fig. 5C.b, inhibition of CRF ${ }^{\mathrm{CeA}-\mathrm{LH} / \mathrm{pSTN}}$ terminals neurons did not affect the overall withdrawal severity $(U=14.00, p>0.05$; Fig. 5C.b, inset). The $t$-test did not indicate an effect of inhibition of $\mathrm{CRF}^{\mathrm{CeA}-\mathrm{LH} / \mathrm{pSTN}}$ terminals on saccharin self-administration $\left(t_{5}=\right.$ 1.024, $p>0.05$; Fig. 5C.c).

Parabrachial nucleus. The two-way repeated-measures ANOVA, with time and laser as withinsubjects factors, revealed a significant effect of time $\left(F_{2,22}=7.14, p<0.01\right)$ but no effect of laser $\left(F_{1,11}=0.73, p>0.05\right)$ and no time $\times$ laser interaction $\left(F_{2,22}=1.99, p>0.05\right)$. A separate oneway ANOVA indicated that the animals exhibited escalation of alcohol intake compared with baseline pre-vapor exposure $\left(F_{6,66}=4.75, p<0.001\right)$. The escalation of alcohol intake was 
unaffected by optogenetic inhibition of $\mathrm{CRF}^{\mathrm{CeA}-\mathrm{PBN}}$ terminals, indicated by the Newman Keuls post hoc tests (Fig. 5D.a). Immediately before the last two alcohol self-administration sessions, the rats were observed for withdrawal signs. As shown in Fig. 5D.b, inhibition of CRF ${ }^{\text {CeA-PBN }}$ terminals did not affect the overall withdrawal severity $(U=18.50, p>0.05$; Fig. 5D.b, inset). The $t$-test did not indicate an effect of inhibition of $\mathrm{CRF}^{\mathrm{CeA}-\mathrm{PBN}}$ terminals on saccharin selfadministration $\left(t_{11}=0.77, p>0.05\right.$; Fig. 5D.c $)$.

\section{Discussion}

The present study demonstrates that CRF neurons represent the majority of neurons that comprise the CeA neuronal ensemble that is recruited during withdrawal in alcohol-dependent rats. We further demonstrated that activation of $\mathrm{CRF}$ neurons in the lateral $\mathrm{CeA}(\mathrm{CeL})$ is required for the recruitment of a CeA neuronal ensemble that is located in the $\mathrm{CeL}$, medial $\mathrm{CeA}(\mathrm{CeM})$, and capsular $\mathrm{CeA}(\mathrm{CeC})$. Optogenetic inhibition of $\mathrm{CeA} \mathrm{CRF}$ neurons fully reversed the escalation of alcohol drinking and partially alleviated the somatic signs of withdrawal in dependent rats, without affecting water or saccharin self-administration. Finally, the selective optogenetic inhibition of $\mathrm{CRF}^{\mathrm{CeA}-\mathrm{BNST}}$ pathways but not $\mathrm{CRF}^{\mathrm{CeA}-\mathrm{SI}}, \mathrm{CRF}^{\mathrm{CeA}-\mathrm{LH} / \mathrm{pSTN}}$, or $\mathrm{CRF}^{\mathrm{CeA}-\mathrm{PBN}}$ pathways recapitulated the behavioral effects of the inactivation of CeA CRF neurons.

Numerous studies have demonstrated that chronic intermittent exposure to alcohol vapor has robust predictive validity for alcoholism and construct validity for the neurobiological mechanisms of alcohol dependence (Heilig and Koob, 2007; Koob, 2009). Rats that are made dependent with chronic intermittent exposure to alcohol vapor (14 h on/10 h off) increase their alcohol drinking when tested during early and protracted withdrawal, with clinically relevant 
blood alcohol levels (150-250 $\mathrm{mg} \%)$ and compulsive alcohol intake despite adverse consequences (Vendruscolo et al, 2012). Compulsive drug seeking that is associated with alcoholism can be derived from multiple neuroadaptations, but a key component involves the construct of negative reinforcement, defined as alcohol drinking to alleviate a negative emotional state (Koob, 2014). The recruitment of brain stress systems, such as CRF, in the extended amygdala has been hypothesized to play central role in generating the negative emotional state that drives such negative reinforcement.

We recently demonstrated that withdrawal from alcohol produces significant recruitment of $\mathrm{Fos}^{+}$neurons in the CeA (de Guglielmo et al, 2016). We found that recruitment of the CeA neuronal ensemble is limited to a small subpopulation of neurons in the $\mathrm{CeA}$, in which double labeling with Fos and NeuN revealed that only $7-8 \%$ of neurons $\left(\mathrm{NeuN}^{+}\right)$were $\mathrm{Fos}^{+}$ (Supplementary Fig. 1). No difference was observed between the different subregions of the CeA, although the lateral CeA (which contains the majority of CRF neurons; (Pomrenze et al, 2015) exhibited the largest increase in $\mathrm{Fos}^{+}$neurons (Supplementary Fig. 1). Moreover, double FosCRF immunohistochemistry showed that the total number of CRF neurons did not change between groups (Fig. 1), but the number of $\mathrm{Fos}^{+} / \mathrm{CRF}^{+}$neurons in the CeA dramatically increased during withdrawal from alcohol. Finally, neuronal phenotyping showed that the CeA withdrawal neuronal ensemble was mostly composed of both $\mathrm{CRF}^{+}$and $\mathrm{CRF}^{-}$neurons, with $\mathrm{CRF}^{+}$neurons representing the majority $(\sim 80 \%)$ of the total number of $\mathrm{Fos}^{+}$neurons.

We previously demonstrated that inactivation of the withdrawal neuronal ensemble in the $\mathrm{CeA}$ reverses the escalation of alcohol drinking in dependent rats and alleviates the somatic signs of withdrawal (de Guglielmo et al, 2016). However, unknown was whether the activation of CeA $\mathrm{CRF}$ neurons is a cause or consequence of recruitment of the $\mathrm{CeA}$ withdrawal neuronal 
ensemble. The results showed that the inactivation of CeA CRF neurons completely prevented recruitment of the CeA neuronal ensemble that includes both $\mathrm{CRF}^{+}$and $\mathrm{CRF}^{-}$neurons. These results are consistent with our previous work showing that chemogenetic stimulation of CeA CRF neurons recruited a population of $\mathrm{CRF}^{+}$and $\mathrm{CRF}^{-}$neurons in the $\mathrm{CeL}$ and $\mathrm{CeM}$ that was prevented (for $\mathrm{CRF}^{-}$neurons) by a $\mathrm{CRF}_{1}$ receptor antagonist (Pomrenze et al, 2015). CeA CRF neurons are $\gamma$-aminobutyric acid (GABA)ergic, and the activation of $\mathrm{CRF}_{1}$ receptors in the $\mathrm{CeL}$ increases glutamate release locally (Silberman and Winder, 2013), suggesting that the recruitment of $\mathrm{CRF}^{-}$neurons in the neuronal ensemble may be mediated by the activation of $\mathrm{CRF}_{1}$ receptors on glutamatergic terminals. Unilateral inhibition might also affect the contralateral CeA, suggesting the partial synchronization of bilateral CeAs. We next evaluated the effects of the optogenetic inhibition of CeA CRF neurons in animals that were trained to selfadminister alcohol and were made dependent by chronic intermittent exposure to alcohol vapor. Crh-Cre rats were infused with AAV-DIO-NpHR-eYFP (eNpHR) or AAV-DIO-eYFP (eYFP) and bilaterally implanted with fiber optics in the CeA. The inactivation of CeA CRF neurons decreased alcohol drinking in dependent rats (Fig. 3). This effect was reversible, and inactivation reversed the level of drinking to pre-escalation levels before the induction of dependence. Altogether, we found that CeA CRF neurons are responsible for activation of the CeA neuronal ensemble and excessive alcohol drinking in dependent rats. Inactivation of CeA CRF neurons had no effect on saccharin self-administration or locomotor activity, and no effect of the laser was observed in the control group (AAV-DIO-eYFP; Fig. 3). These results suggest that the decrease in drinking that was observed with NpHR was specific to alcohol drinking in dependent rats and not attributable to nonspecific alterations of other behaviors. Although we did not observe nonspecific effects of $30 \mathrm{~min}$ inactivation using $532 \mathrm{~nm} / \mathrm{NpHR}$ on behavioral measures, 
one concern may be potential neuroadaptations at the cellular level. To test this possibility, we tested the effects of only $5 \mathrm{~min}$ of the green laser in NpHR-injected rats because inhibition for 5 min using $532 \mathrm{~nm} / \mathrm{NpHR}$ did not produce aberrant or nonspecific neuronal responses (Mahn et al, 2016). We did not observe any qualitative or quantitative differences between the 5 and 30 min exposure times. Indeed, the same effect size between NpHR and YFP rats was observed after 5 min compared with $30 \mathrm{~min}$.

We then tested whether inactivation of the population of CeA CRF neurons during withdrawal would modulate the recruitment of $\mathrm{Fos}^{+}$neurons in the CeA. We implanted Crh-Cre rats with unilateral fiber optics over the $\mathrm{CeA}$ and tested the effect of unilateral inhibition of CeA CRF neurons for $30 \mathrm{~min}$ during withdrawal $(8 \mathrm{~h})$ from chronic intermittent exposure to alcohol as in the previous experiment. Unilateral inhibition of CeA CRF neurons during withdrawal led to the same reduction of alcohol intake that was observed with bilateral inhibition. We also found that somatic withdrawal signs were significantly reduced. We recently found that CeA CRF neurons send dense projections to the BNST, SI, LH/pSTN, and PBN, but the role of each CRF projection in alcohol drinking was unknown.

Inactivation of the $\mathrm{CRF}^{\mathrm{CeA}-\mathrm{BNST}}$ pathway recapitulated the effects of silencing $\mathrm{CeA} \mathrm{CRF}$ cell bodies, demonstrating that activation of the $\mathrm{CRF}^{\mathrm{CeA-BNST}}$ projection is critical for excessive alcohol drinking in dependent rats (Fig. 5). The effect was specific to alcohol drinking and withdrawal since saccharin self-administration was unaffected.

The BNST is considered an integrative hub that connects several stress-related brain regions, including the basolateral amygdala, CeA, and PVN, and brain reward centers, such as the ventral tegmental area and nucleus accumbens (Brog et al, 1993; Georges and Aston-Jones, 2001, 2002; Rinker et al, 2016; Silverman et al, 1981). Importantly, the BNST is a critical 
modulator of addiction-like behavior (Aston-Jones and Druhan, 1999; Pleil et al, 2016). Several neuropeptides, including CRF, innervate and modulate activity in the BNST (Kash et al, 2015). A substantial body of evidence supports the role of CRF signaling in the BNST during anxiety that is induced by withdrawal from drugs of abuse (Huang et al, 2010; Overstreet et al, 2003). These effects on withdrawal are thought to drive the effects of CRF in the BNST on stressinduced reinstatement of drug-seeking behavior (Erb et al, 2001; Erb and Stewart, 1999). The CeA sends dense CRF projections to the ventral and dorsal BNST (Pomrenze et al, 2015; Sakanaka et al, 1986). A clear role for BNST CRF signaling in stress-induced reinstatement has been reported, but less clear is the role of CRF signaling in the BNST in alcohol addiction. For example, although intra-CeA injections of CRF receptor antagonists after chronic intermittent alcohol exposure block chronic intermittent exposure-induced increases in alcohol selfadministration (Funk et al, 2006; Varodayan et al, 2017), intra-BNST injections of the same antagonist post-chronic intermittent alcohol exposure have been shown to be ineffective (Funk et $a l, 2006)$. In the present study, we demonstrated a pivotal role for $\mathrm{CRF}^{\mathrm{CeA}-\mathrm{BNST}}$ projections in excessive alcohol drinking in dependent rats. The reduction of alcohol intake that was observed herein appears to be mediated by ventral BNST projections because they were the target of our fiber optics. We previously observed a lack of CRF cells from the ventral BNST in our Crh-Cre rats (Pomrenze et al, 2015).

No effect was observed in the $\mathrm{CRF}^{\mathrm{CeA}-\mathrm{SI}}, \mathrm{CRF}^{\mathrm{CeA-LH} / \mathrm{pSTN}}$, or $\mathrm{CRF}^{\mathrm{CeA}-\mathrm{PBN}}$. We identified a small portion of fibers that project from the CeA to the SI. Previous studies showed that acute alcohol does not affect $\mathrm{Fos}^{+}$immunoreactivity in the SI (Herring et al, 2004), although chronic alcohol may lead to significant cellular loss in the SI in mice (Beracochea et al, 1987). The SI is a major attentional modulator of prefrontal cortex (PFC) function (Zaborszky et al, 1999). The 
CeA-SI-PFC circuit has not been studied in the context of drug addiction, but converging evidence suggests that it is involved in attentional processes, salience, and learning. We hypothesized that the CeA-SI-PFC pathway could promote alcohol drinking by increasing the salience of negative emotional states and facilitating learning to obtain relief from such emotional states through alcohol drinking. However, this hypothesis was not supported by the results because alcohol drinking and withdrawal signs were unaltered by inhibition of CRF ${ }^{\text {CeA-SI }}$ terminals. Another hypothesis that needs further testing is that $\mathrm{CRF}^{\mathrm{CeA}-\mathrm{SI}}$ terminals might be responsible for cognitive impairments that are caused by excessive alcohol drinking, given that PFC neuron recruitment during alcohol withdrawal predicts cognitive impairment. We observed a functional disconnection between the $\mathrm{CeA}$ and infralimbic/prelimbic cortex during abstinence from binge-like alcohol drinking (George et al, 2012).

The $\mathrm{LH} / \mathrm{pSTN}$ is a major input to the medial habenula $(\mathrm{MH})$-interpeduncular nucleus (IPN) circuit, which has been recently shown to contribute to withdrawal-induced nicotine intake (Grieder et al, 2014; Zhao-Shea et al, 2015). Considering the critical role of the MH-IPN pathway in compulsive nicotine intake and behavioral signs of nicotine withdrawal, we expected that the optogenetic inhibition of $\mathrm{CRF}^{\mathrm{CeA}-\mathrm{LH} / \mathrm{pSTN}}$ terminals would prevent excessive alcohol drinking and somatic signs of alcohol withdrawal. However, we did not observe such effects. Activation of this pathway during withdrawal was not an important factor in excessive drinking or the expression of somatic signs of withdrawal. An alternative hypothesis is that the $\mathrm{CRF}^{\mathrm{CeA}-}$ LH/pSTN pathway is recruited during withdrawal but is specifically involved in the reinstatement of alcohol seeking in the absence of drinking. Indeed, the LH has been shown to be critical for the context-induced reinstatement of alcohol seeking (Moorman et al, 2016). Future studies of the 
context-induced reinstatement of alcohol seeking after the extinction of alcohol drinking are needed to test this hypothesis.

The largest and densest projection from $\mathrm{CRF}^{\mathrm{CeA}-\mathrm{PBN}}$ terminals was identified in the lateral PBN. The CeA receives nociception-related information via a direct monosynaptic pathway from the external part of the lateral PBN (Sarhan et al, 2005; Han et al., 2015 - PMID: 26186190), which is the predominant target of the ascending nociceptive spino-parabrachio-amygdaloid pathway (Jasmin et al, 1997; Todd, 2010). Previous studies showed that nociceptive stimuli increase neuronal activity (Hermanson and Blomqvist, 1996) and Fos immunoreactivity (Bester et al, 1997) in the PBN. The inhibition of $\mathrm{CRF}^{\mathrm{CeA}-\mathrm{PBN}}$ terminals did not affect alcohol drinking or the somatic signs of withdrawal, and one possibility is that the $\mathrm{CRF}^{\mathrm{CeA}-\mathrm{PBN}}$ projection mediates hyperalgesia during withdrawal from alcohol (de Guglielmo et al, 2017; Edwards et al, 2012). Further studies will be required to test this hypothesis.

A large body of evidence shows that CRF and GABA systems in the CeA play an important role in alcohol dependence (Koob, 2008; Menzaghi et al, 1994; Merlo Pich et al, 1995; Valdez and Koob, 2004). At the cellular level, acute alcohol enhances evoked $\mathrm{GABA}_{\mathrm{A}}$ receptormediated inhibitory postsynaptic currents by increasing GABA release in rats (Roberto et al, 2003; Roberto et al, 2004) and mice (Nie et al, 2004). These effects are mediated by CRF and can be blocked by a $\mathrm{CRF}_{1}$ antagonist (Roberto et al, 2010). The effects on alcohol intake that were observed herein were specific to CRF neurons, but we cannot exclude the possibility that they might be mediated by the inactivation of other neurotransmitters, such as CRF, GABA, dynorphin, or somatostatin, considering the high degree of colocalization and overlap between these populations of neurons (Gilpin and Roberto, 2012; Kang-Park et al, 2015; Marchant et al, 2007; Pomrenze et al, 2015). Future studies should identify the neurotransmitters CeA CRF 
neurons release locally and in the BNST to mediate alcohol drinking and withdrawal signs in the dependent state.

In summary, the present study found that the activation of CeA CRF neurons was required for recruitment of the $\mathrm{CeA}$ neuronal ensemble that drives excessive alcohol drinking in dependent rats. Inactivation of the $\mathrm{CRF}^{\mathrm{CeA}-\mathrm{BNST}}$ pathway completely reversed excessive alcohol drinking during withdrawal and partially prevented the somatic signs of withdrawal. Inactivation of the $\mathrm{CRF}^{\mathrm{CeA}-\mathrm{SI}}, \mathrm{CRF}^{\mathrm{CeA}-\mathrm{LH} / \mathrm{pSTN}}$, and $\mathrm{CRF}^{\mathrm{CeA}-\mathrm{PBN}}$ pathways did not impact alcohol drinking or the somatic signs of withdrawal. Future studies will be important to determine whether the $\mathrm{CRF}^{\mathrm{CeA}-\mathrm{SI}}, \mathrm{CRF}^{\mathrm{CeA}-\mathrm{LH} / \mathrm{pSTN}}$, and $\mathrm{CRF}^{\mathrm{CeA}-\mathrm{PBN}}$ pathways are instead involved in mediating other aspects of alcohol dependence, including cognitive impairments, alcohol seeking, and hyperalgesia. These results suggest dissociable roles for CeA CRF pathways in addiction, and targeting the CRF CeA neuronal ensemble or $\mathrm{CRF}^{\mathrm{CeA}-\mathrm{BNST}}$ pathway may facilitate the development of novel therapeutic approaches for the treatment of alcohol use disorders. 


\section{Acknowledgements}

The authors thank Michael Arends for proofreading the manuscript.

\section{Footnotes}

This study was supported by National Institutes of Health [Grant AA006420], [Grant AA020608], [Grant AA022977] (OG), [Grant AA13588], and [Grant AA017072] (ROM). 


\section{References}

Aston-Jones G, Druhan J (1999). Behavioural pharmacology. Breaking the chain of addiction. Nature 400(6742): 317, 319.

Barak S, Liu F, Ben Hamida S, Yowell QV, Neasta J, Kharazia V, et al (2013). Disruption of alcohol-related memories by mTORC1 inhibition prevents relapse. Nat Neurosci 16(8): 11111117.

Beracochea D, Lescaudron L, Verna A, Jaffard R (1987). Neuroanatomical effects of chronic ethanol consumption on dorsomedial and anterior thalamic nuclei and on substantia innominata in mice. Neurosci Lett 73(1): 81-84.

Bester H, Matsumoto N, Besson JM, Bernard JF (1997). Further evidence for the involvement of the spinoparabrachial pathway in nociceptive processes: a c-Fos study in the rat. J Comp Neurol 383(4): 439-458.

Brog JS, Salyapongse A, Deutch AY, Zahm DS (1993). The patterns of afferent innervation of the core and shell in the "accumbens" part of the rat ventral striatum: immunohistochemical detection of retrogradely transported fluoro-gold. J Comp Neurol 338(2): 255-278.

de Guglielmo G, Crawford E, Kim S, Vendruscolo LF, Hope BT, Brennan M, et al (2016). Recruitment of a Neuronal Ensemble in the Central Nucleus of the Amygdala Is Required for Alcohol Dependence. The Journal of neuroscience : the official journal of the Society for Neuroscience 36(36): 9446-9453.

de Guglielmo G, Kallupi M, Cole MD, George O (2017). Voluntary induction and maintenance of alcohol dependence in rats using alcohol vapor self-administration. Psychopharmacology (Berl).

Deisseroth K (2012). Predicted irradiance values: Model based on direct measurements in mammalian brain tissue.

Edwards S, Vendruscolo LF, Schlosburg JE, Misra KK, Wee S, Park PE, et al (2012). Development of mechanical hypersensitivity in rats during heroin and ethanol dependence: alleviation by CRF(1) receptor antagonism. Neuropharmacology 62(2): 1142-1151.

Erb S, Salmaso N, Rodaros D, Stewart J (2001). A role for the CRF-containing pathway from central nucleus of the amygdala to bed nucleus of the stria terminalis in the stress-induced reinstatement of cocaine seeking in rats. Psychopharmacology (Berl) 158(4): 360-365.

Erb S, Stewart J (1999). A role for the bed nucleus of the stria terminalis, but not the amygdala, in the effects of corticotropin-releasing factor on stress-induced reinstatement of cocaine seeking. The Journal of neuroscience : the official journal of the Society for Neuroscience 19(20): RC35. 
Funk CK, O'Dell LE, Crawford EF, Koob GF (2006). Corticotropin-releasing factor within the central nucleus of the amygdala mediates enhanced ethanol self-administration in withdrawn, ethanol-dependent rats. The Journal of neuroscience : the official journal of the Society for Neuroscience 26(44): 11324-11332.

Funk CK, Zorrilla EP, Lee MJ, Rice KC, Koob GF (2007). Corticotropin-releasing factor 1 antagonists selectively reduce ethanol self-administration in ethanol-dependent rats. Biological psychiatry 61(1): 78-86.

Gehlert DR, Cippitelli A, Thorsell A, Le AD, Hipskind PA, Hamdouchi C, et al (2007). 3-(4Chloro-2-morpholin-4-yl-thiazol-5-yl)-8-(1-ethylpropyl)-2,6-dimethyl-imidazo [1,2b]pyridazine: a novel brain-penetrant, orally available corticotropin-releasing factor receptor 1 antagonist with efficacy in animal models of alcoholism. The Journal of neuroscience : the official journal of the Society for Neuroscience 27(10): 2718-2726.

George O, Sanders C, Freiling J, Grigoryan E, Vu S, Allen CD, et al (2012). Recruitment of medial prefrontal cortex neurons during alcohol withdrawal predicts cognitive impairment and excessive alcohol drinking. Proc Natl Acad Sci U S A 109(44): 18156-18161.

Georges F, Aston-Jones G (2001). Potent regulation of midbrain dopamine neurons by the bed nucleus of the stria terminalis. The Journal of neuroscience : the official journal of the Society for Neuroscience 21(16): RC160.

Georges F, Aston-Jones G (2002). Activation of ventral tegmental area cells by the bed nucleus of the stria terminalis: a novel excitatory amino acid input to midbrain dopamine neurons. The Journal of neuroscience : the official journal of the Society for Neuroscience 22(12): 5173-5187.

Gilpin NW, Roberto M (2012). Neuropeptide modulation of central amygdala neuroplasticity is a key mediator of alcohol dependence. Neurosci Biobehav Rev 36(2): 873-888.

Gradinaru V, Mogri M, Thompson KR, Henderson JM, Deisseroth K (2009). Optical deconstruction of parkinsonian neural circuitry. Science 324(5925): 354-359.

Grieder TE, Herman MA, Contet C, Tan LA, Vargas-Perez H, Cohen A, et al (2014). VTA CRF neurons mediate the aversive effects of nicotine withdrawal and promote intake escalation. Nat Neurosci 17(12): 1751-1758.

Haubensak W, Kunwar PS, Cai H, Ciocchi S, Wall NR, Ponnusamy R, et al (2010). Genetic dissection of an amygdala microcircuit that gates conditioned fear. Nature 468(7321): 270-276.

Heilig M, Koob GF (2007). A key role for corticotropin-releasing factor in alcohol dependence. Trends in neurosciences 30(8): 399-406.

Hermanson O, Blomqvist A (1996). Subnuclear localization of FOS-like immunoreactivity in the rat parabrachial nucleus after nociceptive stimulation. J Comp Neurol 368(1): 45-56. 
Herring BE, Mayfield RD, Camp MC, Alcantara AA (2004). Ethanol-induced Fos immunoreactivity in the extended amygdala and hypothalamus of the rat brain: focus on cholinergic interneurons of the nucleus accumbens. Alcohol Clin Exp Res 28(4): 588-597.

Huang MM, Overstreet DH, Knapp DJ, Angel R, Wills TA, Navarro M, et al (2010). Corticotropin-releasing factor (CRF) sensitization of ethanol withdrawal-induced anxiety-like behavior is brain site specific and mediated by CRF-1 receptors: relation to stress-induced sensitization. The Journal of pharmacology and experimental therapeutics 332(1): 298-307.

Janak PH, Tye KM (2015). From circuits to behaviour in the amygdala. Nature 517(7534): 284292.

Jasmin L, Burkey AR, Card JP, Basbaum AI (1997). Transneuronal labeling of a nociceptive pathway, the spino-(trigemino-)parabrachio-amygdaloid, in the rat. The Journal of neuroscience : the official journal of the Society for Neuroscience 17(10): 3751-3765.

Kang-Park M, Kieffer BL, Roberts AJ, Siggins GR, Moore SD (2015). Interaction of CRF and kappa opioid systems on GABAergic neurotransmission in the mouse central amygdala. The Journal of pharmacology and experimental therapeutics 355(2): 206-211.

Kash TL, Pleil KE, Marcinkiewcz CA, Lowery-Gionta EG, Crowley N, Mazzone C, et al (2015). Neuropeptide regulation of signaling and behavior in the BNST. Mol Cells 38(1): 1-13.

Koob GF (2008). A role for brain stress systems in addiction. Neuron 59(1): 11-34.

Koob GF (2009). Brain stress systems in the amygdala and addiction. Brain Res 1293: 61-75.

Koob GF (2014). Neurocircuitry of alcohol addiction: synthesis from animal models. Handb Clin Neurol 125: 33-54.

Koob GF, Ahmed SH, Boutrel B, Chen SA, Kenny PJ, Markou A, et al (2004). Neurobiological mechanisms in the transition from drug use to drug dependence. Neurosci Biobehav Rev 27(8): 739-749.

Macey DJ, Schulteis G, Heinrichs SC, Koob GF (1996). Time-dependent quantifiable withdrawal from ethanol in the rat: effect of method of dependence induction. Alcohol 13(2): 163-170.

Mahn M, Prigge M, Ron S, Levy R, Yizhar O (2016). Biophysical constraints of optogenetic inhibition at presynaptic terminals. Nature neuroscience 19(4): 554-556.

Marchant NJ, Densmore VS, Osborne PB (2007). Coexpression of prodynorphin and corticotrophin-releasing hormone in the rat central amygdala: evidence of two distinct endogenous opioid systems in the lateral division. J Comp Neurol 504(6): 702-715. 
Menzaghi F, Rassnick S, Heinrichs S, Baldwin H, Pich EM, Weiss F, et al (1994). The role of corticotropin-releasing factor in the anxiogenic effects of ethanol withdrawal. Ann NY Acad Sci 739: $176-184$.

Merlo Pich E, Lorang M, Yeganeh M, Rodriguez de Fonseca F, Raber J, Koob GF, et al (1995). Increase of extracellular corticotropin-releasing factor-like immunoreactivity levels in the amygdala of awake rats during restraint stress and ethanol withdrawal as measured by microdialysis. The Journal of neuroscience : the official journal of the Society for Neuroscience 15(8): 5439-5447.

Moorman DE, James MH, Kilroy EA, Aston-Jones G (2016). Orexin/hypocretin neuron activation is correlated with alcohol seeking and preference in a topographically specific manner. The European journal of neuroscience.

Nie Z, Schweitzer P, Roberts AJ, Madamba SG, Moore SD, Siggins GR (2004). Ethanol augments GABAergic transmission in the central amygdala via CRF1 receptors. Science 303(5663): 1512-1514.

Olive MF, Koenig HN, Nannini MA, Hodge CW (2002). Elevated extracellular CRF levels in the bed nucleus of the stria terminalis during ethanol withdrawal and reduction by subsequent ethanol intake. Pharmacol Biochem Behav 72(1-2): 213-220.

Overstreet DH, Knapp DJ, Moy SS, Breese GR (2003). A 5-HT1A agonist and a 5-HT2c antagonist reduce social interaction deficit induced by multiple ethanol withdrawals in rats. Psychopharmacology (Berl) 167(4): 344-352.

Paxinos G, Watson C (2005). The rat brain in stereotaxic coordinates, 5 edn. Elsevier Academic Press: Amsterdam.

Pleil KE, Helms CM, Sobus JR, Daunais JB, Grant KA, Kash TL (2016). Effects of chronic alcohol consumption on neuronal function in the non-human primate BNST. Addict Biol 21(6): 1151-1167.

Pomrenze MB, Millan EZ, Hopf FW, Keiflin R, Maiya R, Blasio A, et al (2015). A Transgenic Rat for Investigating the Anatomy and Function of Corticotrophin Releasing Factor Circuits. Front Neurosci 9: 487.

Rinker JA, Marshall SA, Mazzone CM, Lowery-Gionta EG, Gulati V, Pleil KE, et al (2016). Extended Amygdala to Ventral Tegmental Area Corticotropin-Releasing Factor Circuit Controls Binge Ethanol Intake. Biol Psychiatry.

Roberto M, Cruz MT, Gilpin NW, Sabino V, Schweitzer P, Bajo M, et al (2010). Corticotropin releasing factor-induced amygdala gamma-aminobutyric Acid release plays a key role in alcohol dependence. Biological psychiatry 67(9): 831-839. 
Roberto M, Gilpin NW, Siggins GR (2012). The central amygdala and alcohol: role of gammaaminobutyric acid, glutamate, and neuropeptides. Cold Spring Harb Perspect Med 2(12): a012195.

Roberto M, Madamba SG, Moore SD, Tallent MK, Siggins GR (2003). Ethanol increases GABAergic transmission at both pre- and postsynaptic sites in rat central amygdala neurons. Proc Natl Acad Sci U S A 100(4): 2053-2058.

Roberto M, Madamba SG, Stouffer DG, Parsons LH, Siggins GR (2004). Increased GABA release in the central amygdala of ethanol-dependent rats. The Journal of neuroscience : the official journal of the Society for Neuroscience 24(45): 10159-10166.

Sakanaka M, Shibasaki T, Lederis K (1986). Distribution and efferent projections of corticotropin-releasing factor-like immunoreactivity in the rat amygdaloid complex. Brain Res 382(2): 213-238.

Sarhan M, Freund-Mercier MJ, Veinante P (2005). Branching patterns of parabrachial neurons projecting to the central extended amgydala: single axonal reconstructions. J Comp Neurol 491(4): 418-442.

Silverman AJ, Hoffman DL, Zimmerman EA (1981). The descending afferent connections of the paraventricular nucleus of the hypothalamus (PVN). Brain Res Bull 6(1): 47-61.

Todd AJ (2010). Neuronal circuitry for pain processing in the dorsal horn. Nat Rev Neurosci 11(12): 823-836.

Tye KM, Prakash R, Kim SY, Fenno LE, Grosenick L, Zarabi H, et al (2011). Amygdala circuitry mediating reversible and bidirectional control of anxiety. Nature 471(7338): 358-362.

Valdez GR, Koob GF (2004). Allostasis and dysregulation of corticotropin-releasing factor and neuropeptide Y systems: implications for the development of alcoholism. Pharmacol Biochem Behav 79(4): 671-689.

Varodayan FP, de Guglielmo G, Logrip ML, George O, Roberto M (2017). Alcohol Dependence Disrupts Amygdalar L-Type Voltage-Gated Calcium Channel Mechanisms. The Journal of neuroscience : the official journal of the Society for Neuroscience 37(17): 4593-4603.

Vendruscolo LF, Barbier E, Schlosburg JE, Misra KK, Whitfield TW, Jr., Logrip ML, et al (2012). Corticosteroid-dependent plasticity mediates compulsive alcohol drinking in rats. $J$ Neurosci 32(22): 7563-7571.

Vendruscolo LF, Roberts AJ (2014). Operant alcohol self-administration in dependent rats: focus on the vapor model. Alcohol 48(3): 277-286.

Yizhar O, Fenno LE, Davidson TJ, Mogri M, Deisseroth K (2011). Optogenetics in neural systems. Neuron 71(1): 9-34. 
Zaborszky L, Pang K, Somogyi J, Nadasdy Z, Kallo I (1999). The basal forebrain corticopetal system revisited. Ann N Y Acad Sci 877: 339-367.

Zhao S, Ting JT, Atallah HE, Qiu L, Tan J, Gloss B, et al (2011). Cell type-specific channelrhodopsin-2 transgenic mice for optogenetic dissection of neural circuitry function. Nat Methods 8(9): 745-752.

Zhao-Shea R, DeGroot SR, Liu L, Vallaster M, Pang X, Su Q, et al (2015). Increased CRF signalling in a ventral tegmental area-interpeduncular nucleus-medial habenula circuit induces anxiety during nicotine withdrawal. Nat Commun 6: 6770. 


\section{Figure Legends}

Figure 1. Alcohol withdrawal recruits CRF neurons in the CEA. (A) Escalation of alcohol drinking after chronic intermittent alcohol exposure. ${ }^{* *} p<0.01$, vs. baseline. (B) Number of Fos + nuclei per $\mathrm{mm}^{2}$ in the CeA. (C) Double Fos-CRF immunohistochemistry showed that the total number of CRF neurons did not change between withdrawal rats and naive rats, but (D) the number of Fos $+/ \mathrm{CRF}+$ neurons in the CeA dramatically increased during withdrawal. (E, F) Representative pictures of double Fos-CRF immunohistochemistry in the CeA in naive (E) and alcohol withdrawal $(\mathbf{F})$ rats. The data are expressed as mean \pm SEM. $* * p<0.01, * * * p<0.001$, vs. naive.

Figure 2. Validation of the Crh-Cre rat. (A) Cre-dependent eYFP expression in the CeA. (B) Cre-dependent eYFP colocalizes with CRF immunoreactivity in the CeA. (C) Infrared (Left) and YFP fluorescence (middle) images of a CeA neuron. (Right) Current clamp recording of the same neuron (held at $-50 \mathrm{mV}$ ), depicting hyperpolarization in response to delivery of a $6.5 \mathrm{~s}$ train (asterisks) of green light. (D) In this CeA neuron (held at $-52 \mathrm{mV}$ ) that did not present fluorescence, similar light stimulation did not elicit a response.

Figure 3. (A) Effect of optogenetic inhibition of CeA CRF neurons on alcohol (a) and water (b) self-administration in non-dependent rats. (B) Escalation of alcohol self-administration during alcohol vapor exposure. ${ }^{*} p<0.05, v s$. baseline. (C) Effect of optogenetic inhibition of CeA CRF neurons on alcohol (a) and water (b) self-administration in alcohol-dependent rats. ${ }^{\#} p<0.05$, vs. baseline $(\mathrm{BSL}) ; * * p<0.01, v s$. Escalation. (D) Effect of optogenetic inhibition of CeA CRF neurons on saccharin (a) and water (b) self-administration. (E, F) Effect of optogenetic 
inhibition of CeA CRF neurons on total distance traveled (E) and time spent in the center $(\mathbf{F})$ in the open field test. The data are expressed as mean \pm SEM.

Figure 4. (A) Representative images of NpHR injection in the CeA. (B) Time-course of the effect of unilateral optogenetic inactivation of CeA CRF neurons. ${ }^{*} p<0.05, v s$. baseline (BSL); $* * p<0.01$, vs. laser OFF. (C) Effect of CeA CRF neuron inhibition on somatic withdrawal signs. ${ }^{*} p<0.05$, vs. laser OFF. (D) Effect of unilateral optogenetic inhibition of CeA-CRF neurons on saccharin self-administration. (E) Effect of CeA CRF neuron inhibition for $30 \mathrm{~min}$ during withdrawal $(8 \mathrm{~h})$ from chronic intermittent alcohol exposure on CeA Fos immunoreactivity. ${ }^{\# \#} p<0.01, v s$. naive; ${ }^{*} p<0.05,{ }^{* *} p<0.01$, vs. laser OFF; ${ }^{+} p<0.05, v s$. contralateral. (F-I) Representative pictures of the different experimental conditions.

Figure 5. The schematic diagram shows representative images of the area of injection $(\mathrm{CeA})$ and area of optogenetic inhibition (BNST, SI, LH, and PBN). (A.a) Time-course of the effect of unilateral optogenetic inactivation of CeA CRF BNST terminals. ${ }^{*} p<0.05$, vs. baseline (BSL); $*^{*} p<0.01, v s$. laser OFF. (A.b) Effect of CRF ${ }^{\mathrm{CeA}-\mathrm{BNST}}$ terminal inhibition on somatic withdrawal signs. ${ }^{*} p<0.05$, vs. laser OFF. (A.c) Effect of unilateral optogenetic inhibition of CRF ${ }^{\text {CeA-BNST }}$ terminals on saccharin self-administration. (B.a) Time-course of the effect of unilateral optogenetic inactivation of $\mathrm{CRF}^{\mathrm{CeA}-\mathrm{SI}}$ terminals. ${ }^{\#} p<0.05, v s$. BSL. (B.b) Effect of CRF ${ }^{\mathrm{CeA}-\mathrm{SI}}$ terminal inhibition on somatic withdrawal signs. (B.c) Effect of unilateral optogenetic inhibition of $\mathrm{CRF}^{\mathrm{CeA}-\mathrm{SI}}$ terminals on saccharin self-administration. (C.a) Time-course of the effect of unilateral optogenetic inactivation of $\mathrm{CRF}^{\mathrm{CeA}-\mathrm{LH}}$ terminals. (C.b) Effect of $\mathrm{CRF}^{\mathrm{CeA}-\mathrm{LH}}$ terminal inhibition on somatic withdrawal signs. (C.c) Effect of unilateral optogenetic inhibition of 
$\mathrm{CRF}^{\mathrm{CeA}-\mathrm{LH}}$ terminals on saccharin self-administration. (D.a) Time-course of the effect of unilateral optogenetic inactivation of $\mathrm{CRF}^{\mathrm{CeA}-\mathrm{PBN}}$ terminals. ${ }^{*} p<0.05, v s . \mathrm{BSL} ;{ }^{* *} p<0.01, v s$. laser OFF. (D.b) Effect of $\mathrm{CRF}^{\mathrm{CeA}-\mathrm{PBN}}$ terminal inhibition on somatic withdrawal signs. ${ }^{*} p<$ 0.05 , vs. laser OFF. (D.c) Effect of unilateral optogenetic inhibition of $\mathrm{CRF}^{\mathrm{CeA}-\mathrm{PBN}}$ terminals on saccharin self-administration. 
A)

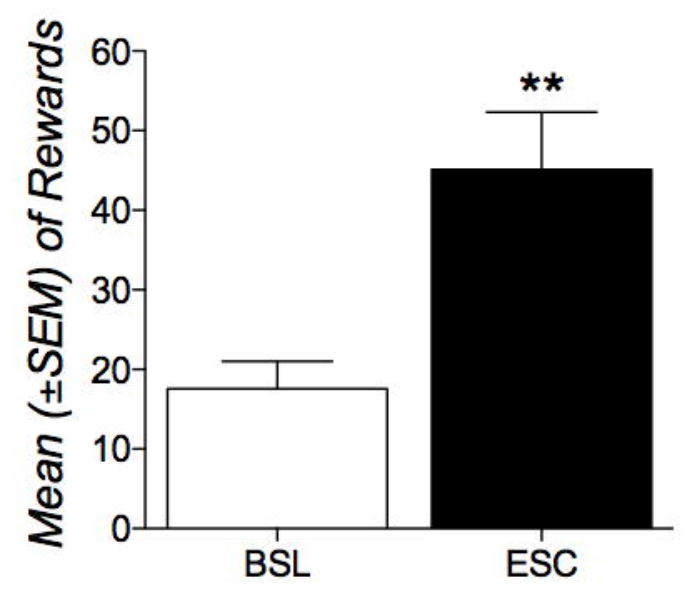

C)

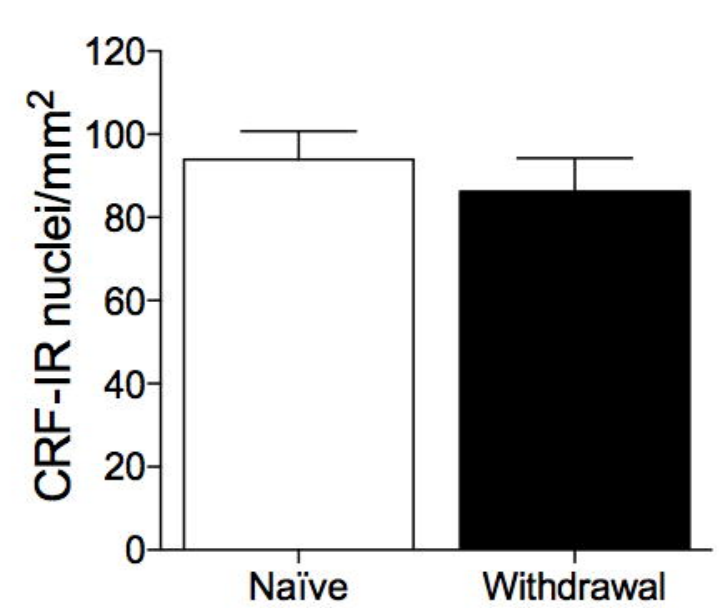

B)

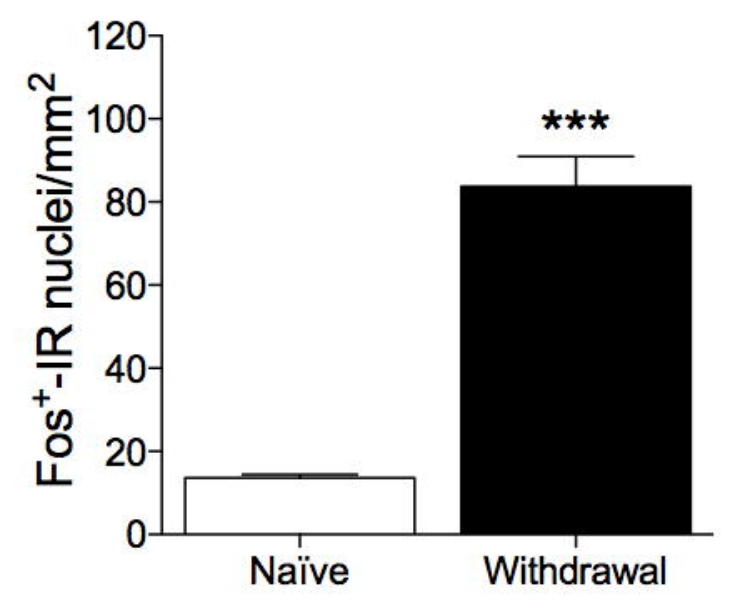

D)

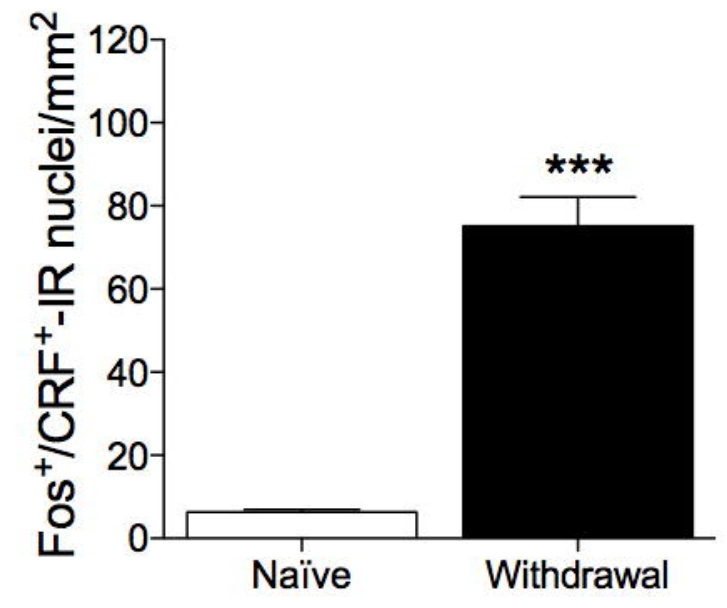

E)

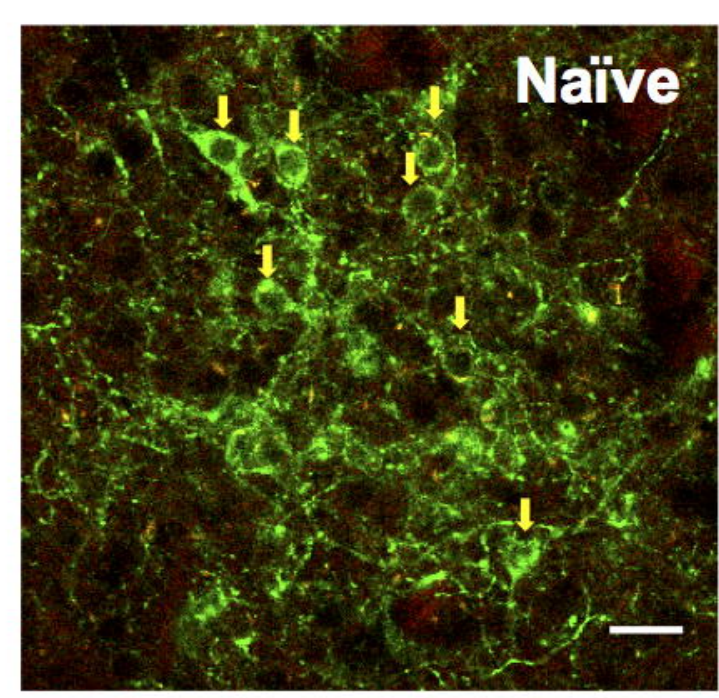

F)

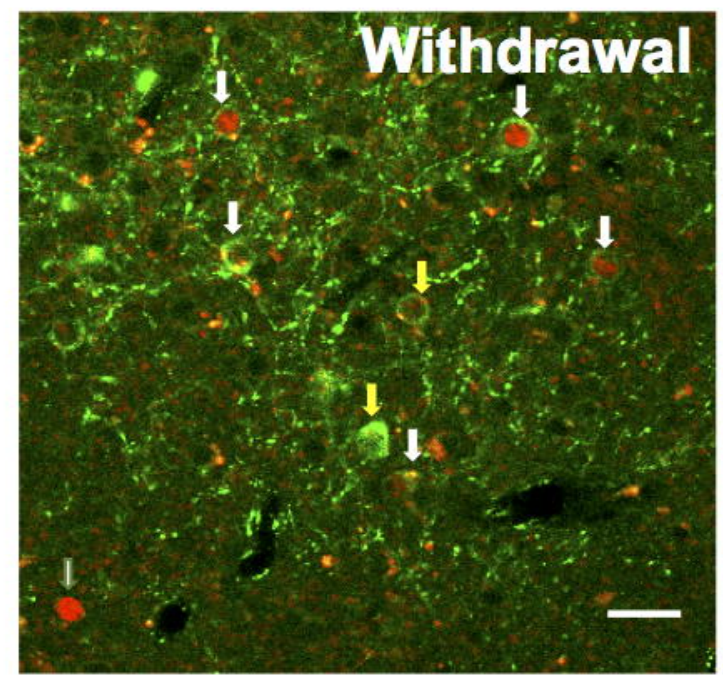


A)

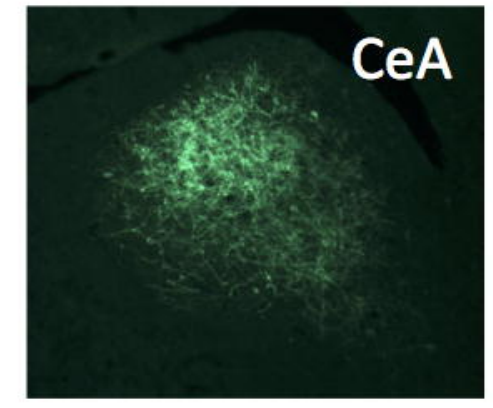

C)

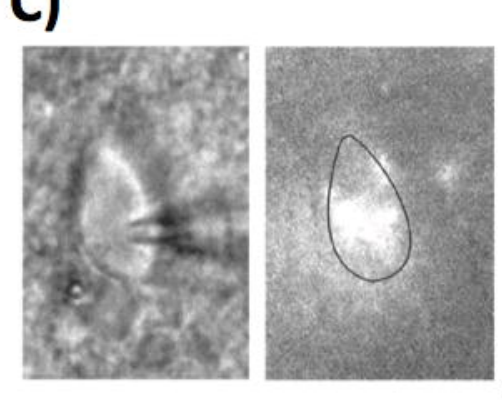

D)

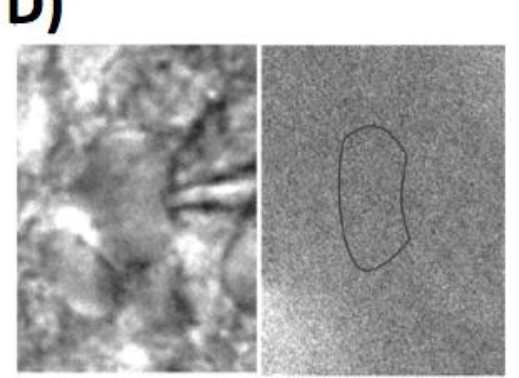

B)
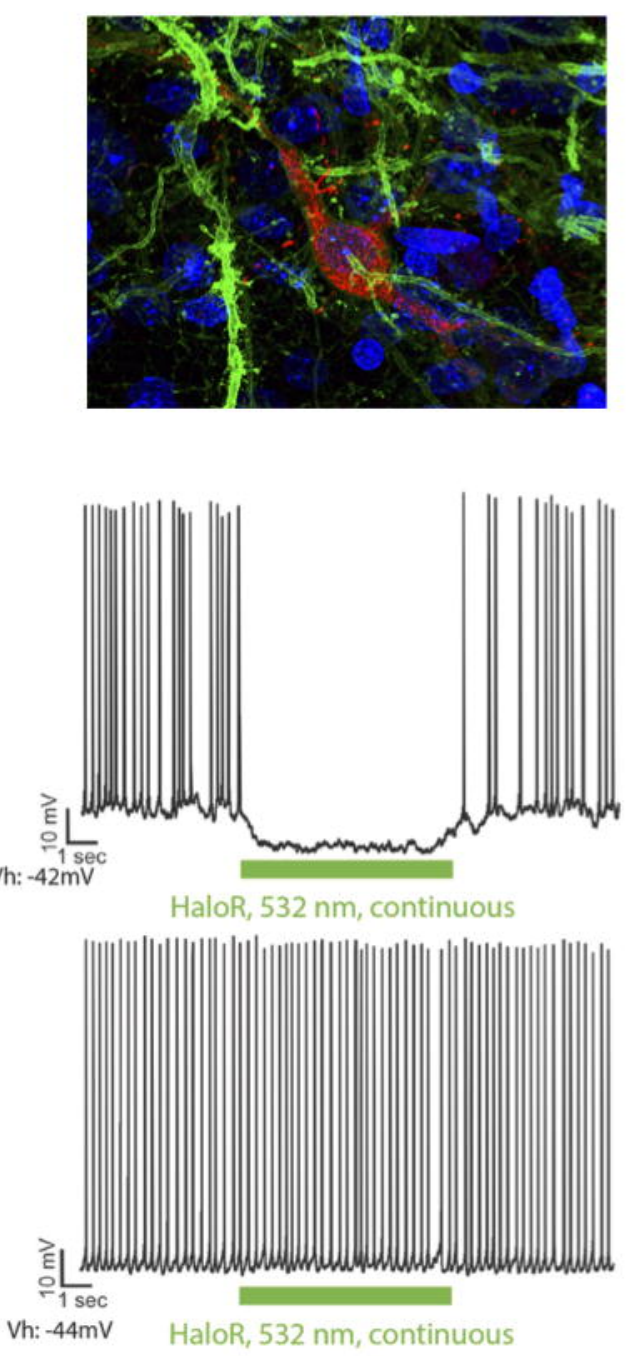
A)

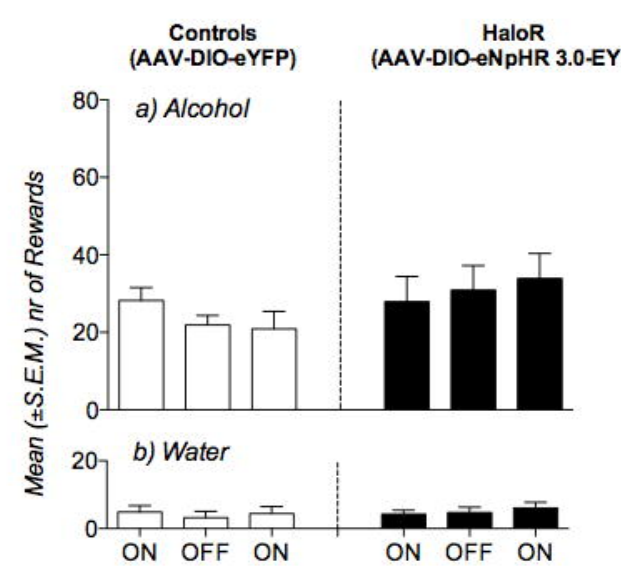

D)

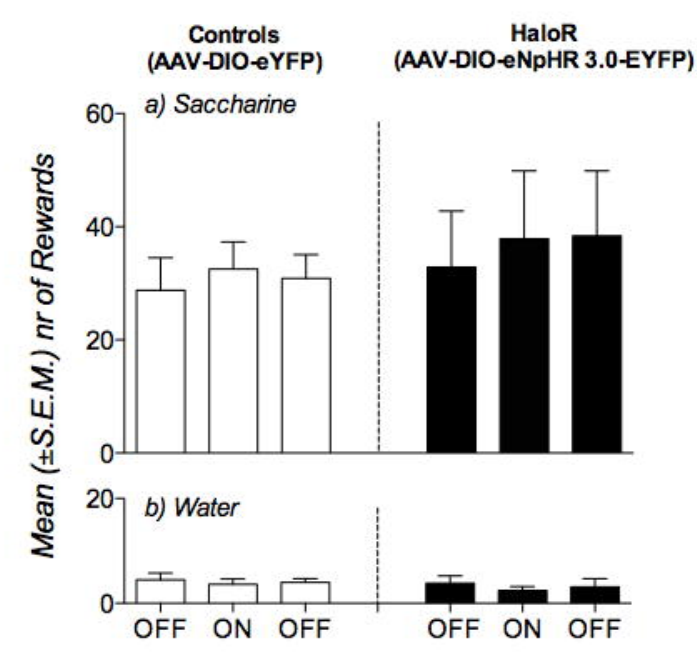

B)

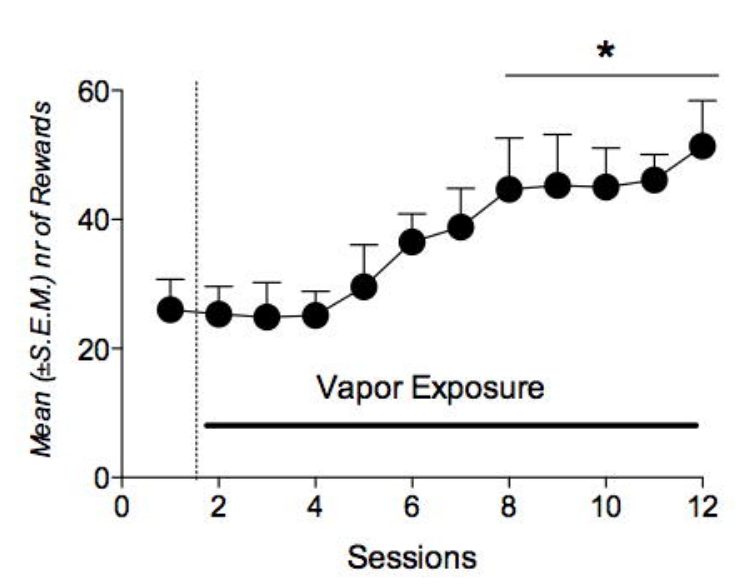

E)

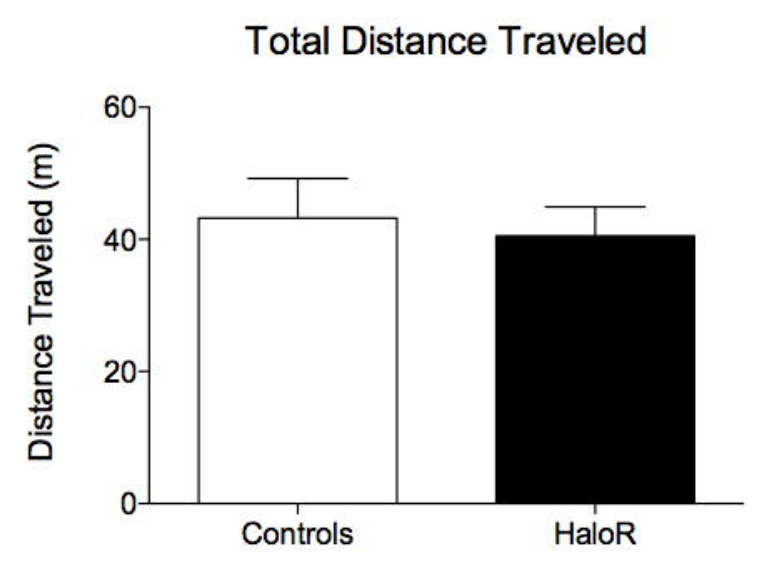

C)

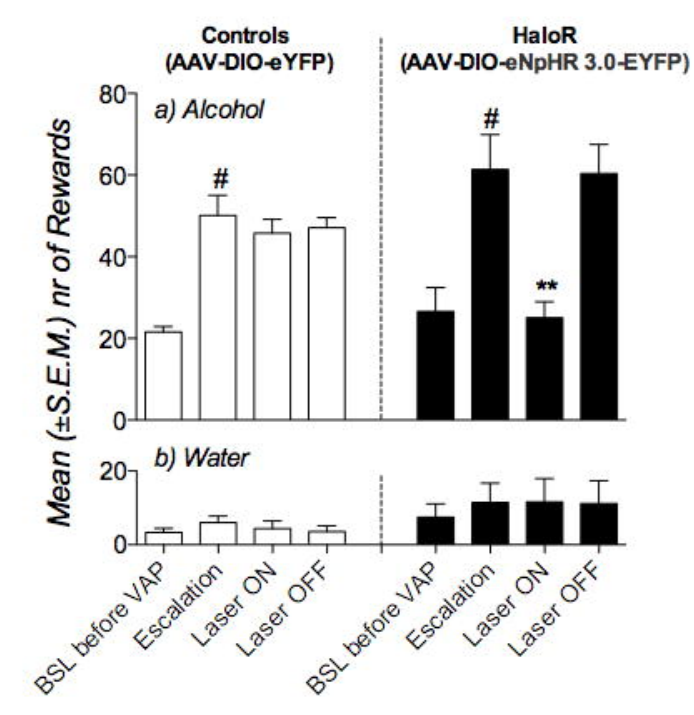

F)

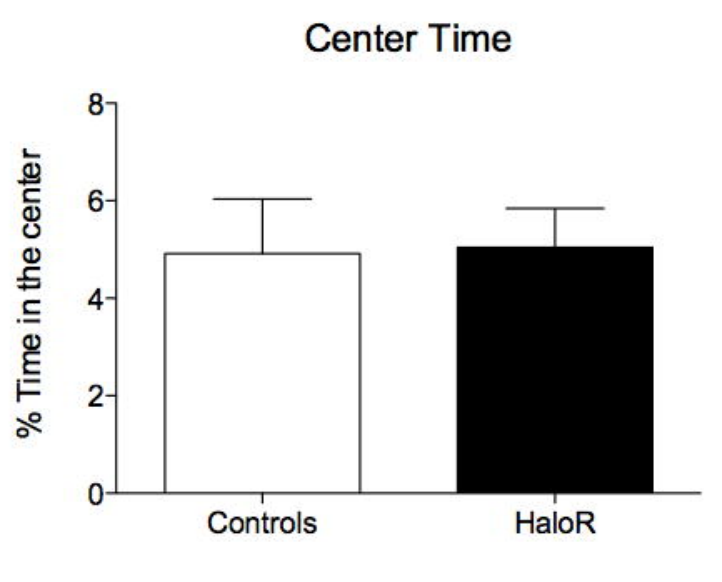


A) AAV-Ef1 $\alpha$-DIO-eNpHR3.0-eYFP
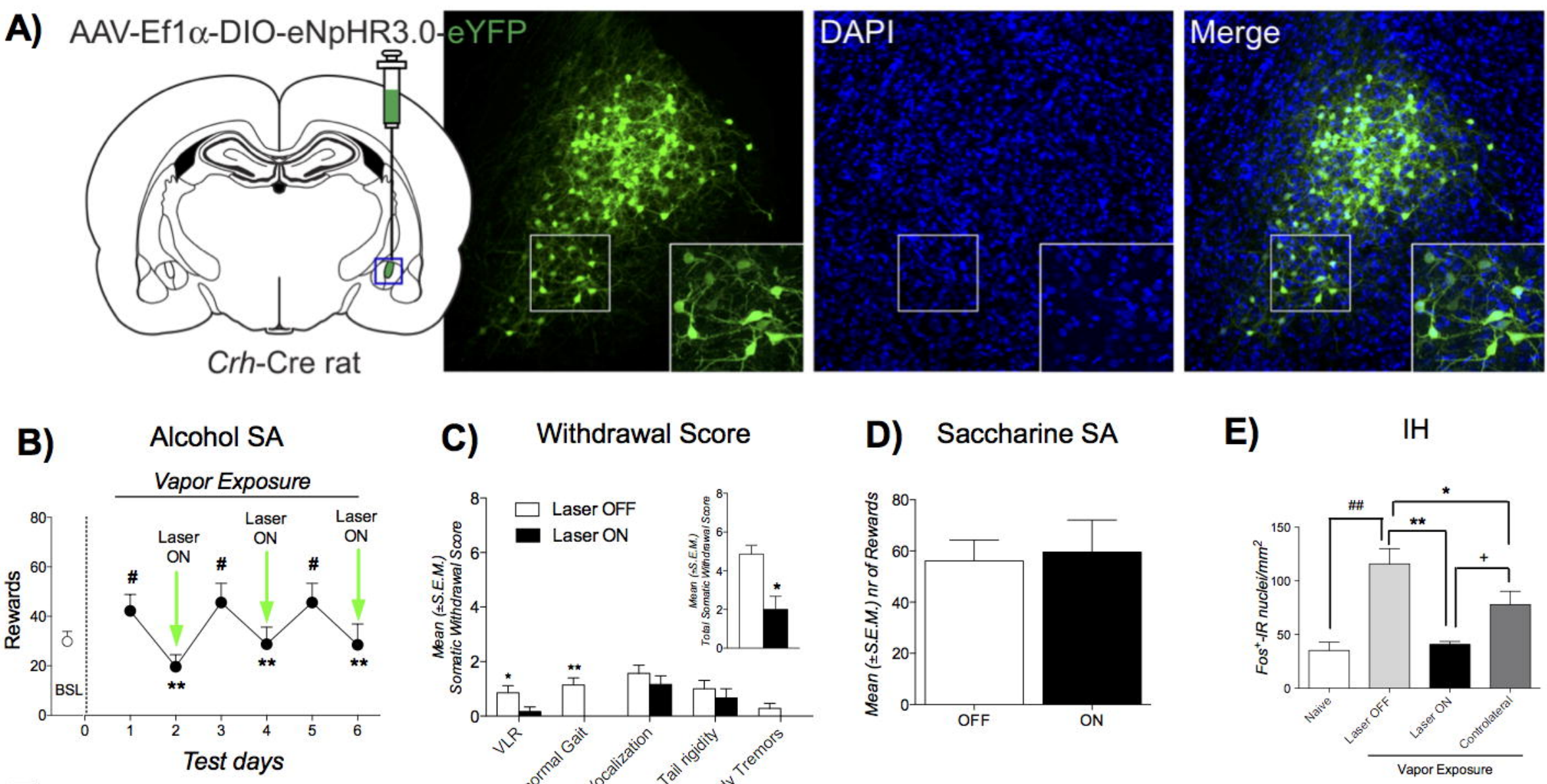

C) Withdrawal Score

D) Saccharine $\mathrm{SA}$

E)

$\mathrm{IH}$

F)

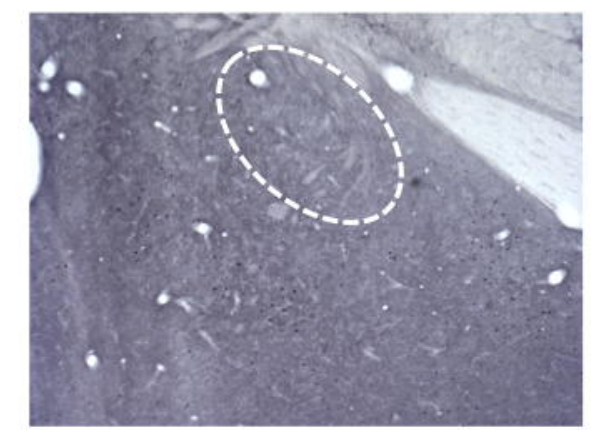

Naïve
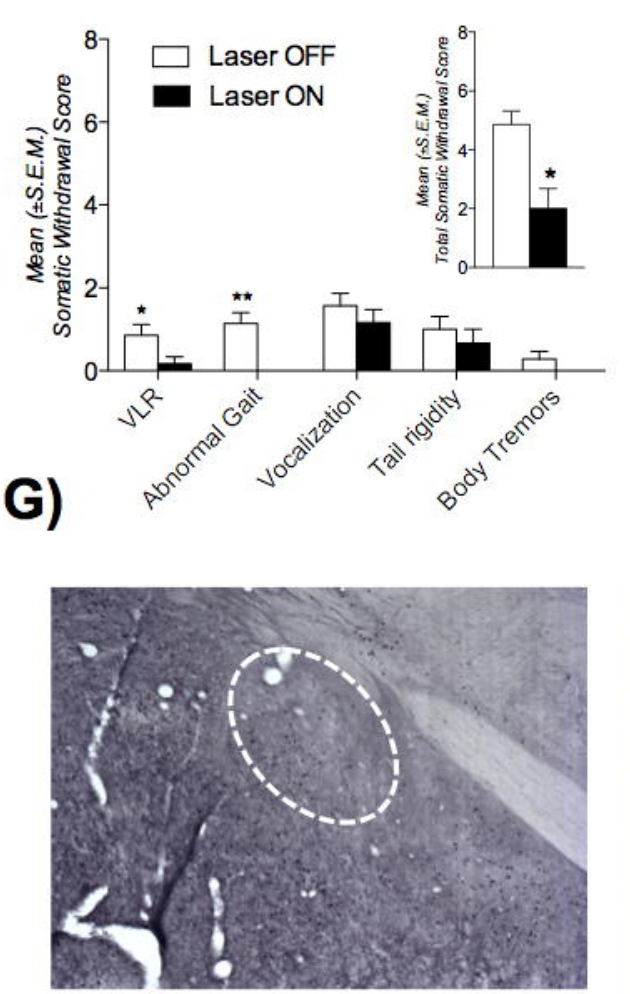

Laser OFF

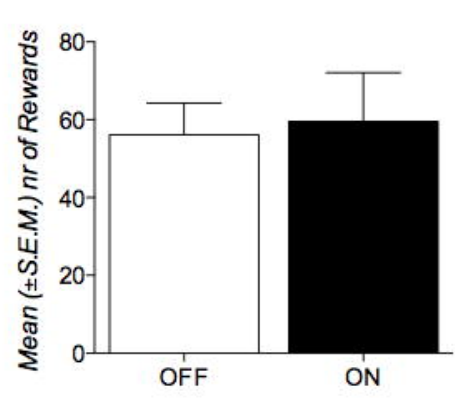

H)

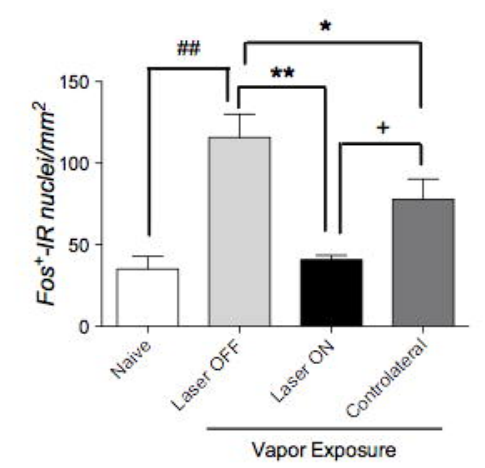

l)

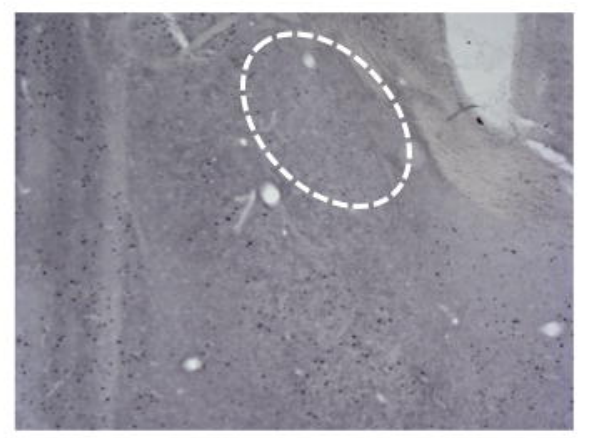

Laser ON

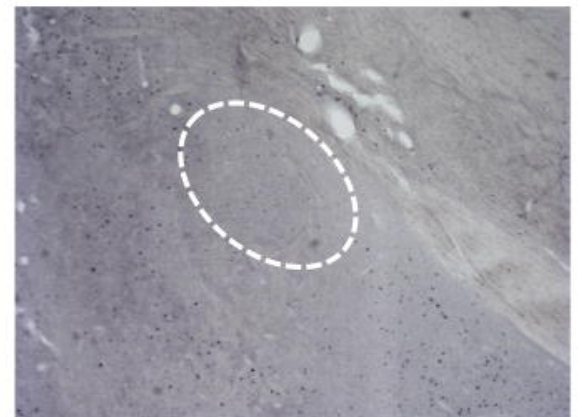

Laser ON/Controlateral 

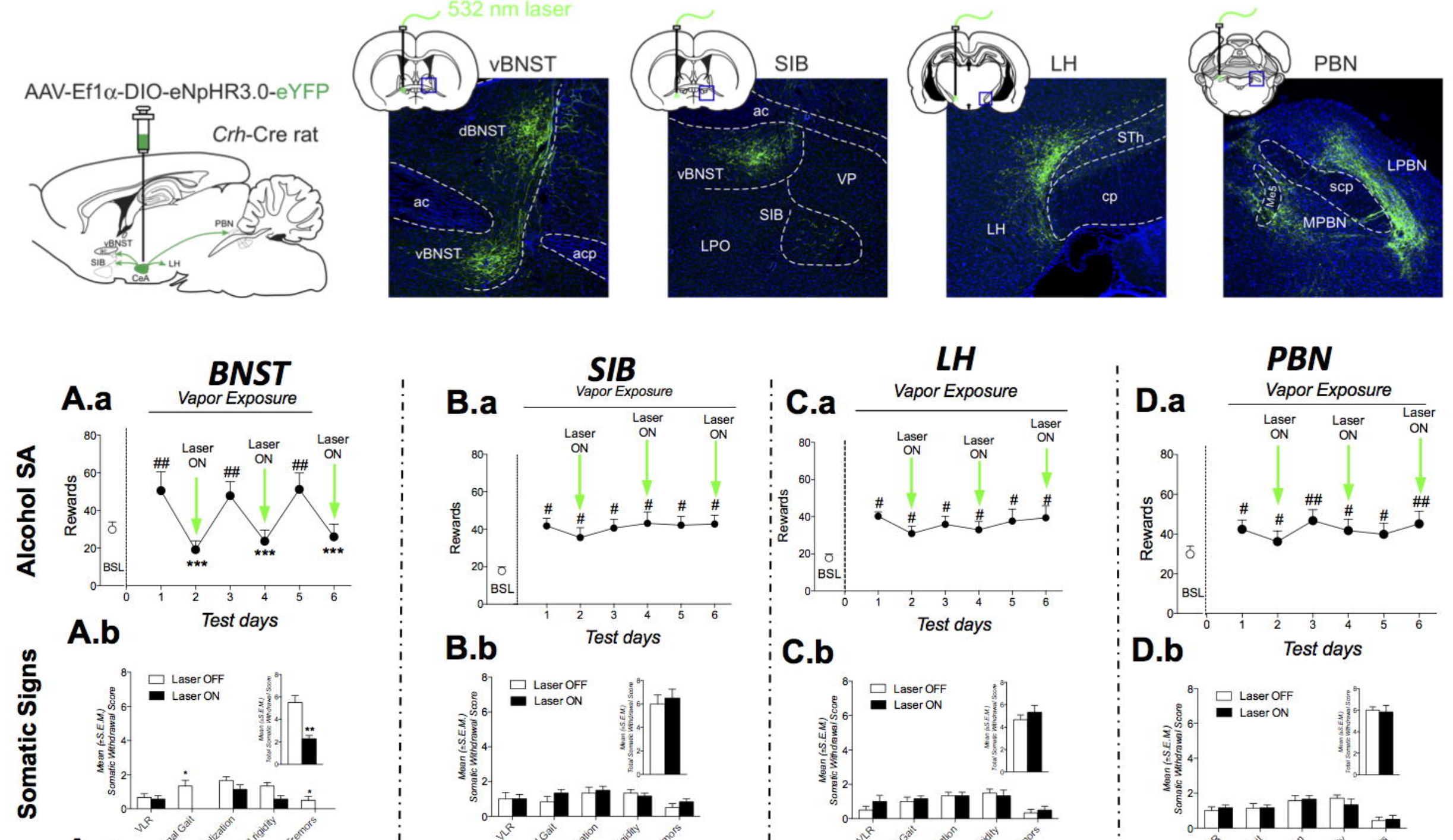

A.c

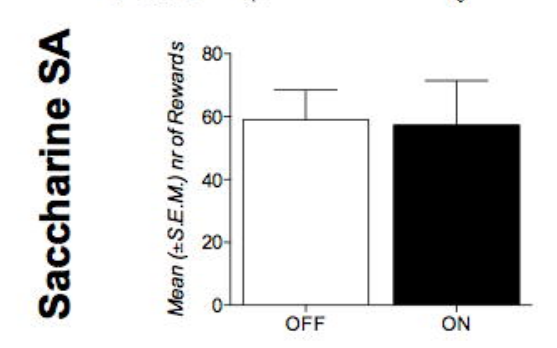

B.C

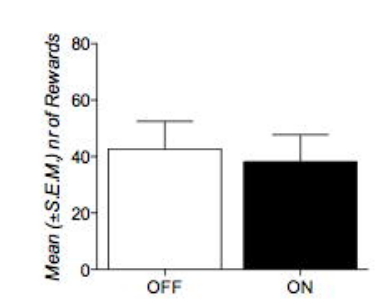

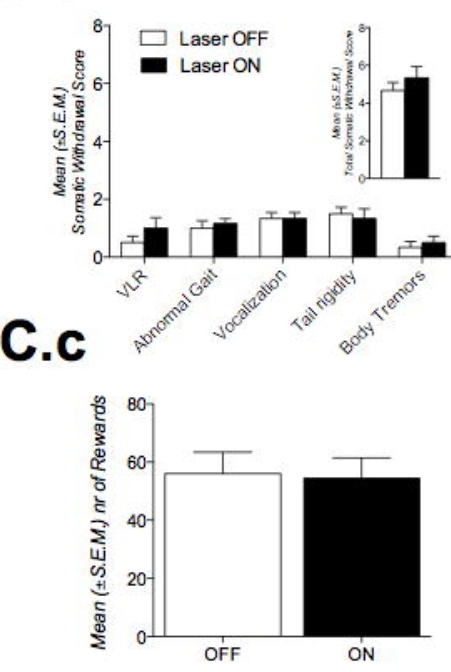

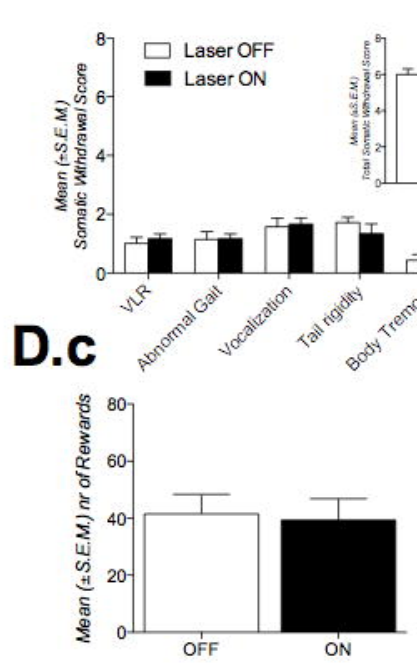

